\title{
Clinical Pharmacokinetic Characteristics of Cebranopadol, a Novel First-in-Class Analgesic
}

\author{
Elke Kleideiter ${ }^{1}$ (D) Chiara Piana ${ }^{2} \cdot$ Shaonan Wang $^{2} \cdot$ Robert Nemeth $^{3} \cdot$ \\ Michael Gautrois ${ }^{4}$
}

Published online: 16 June 2017

(c) The Author(s) 2017. This article is an open access publication

\begin{abstract}
Background and Objectives Cebranopadol is a novel firstin-class analgesic acting as a nociceptin/orphanin FQ peptide and opioid peptide receptor agonist with central analgesic activity. It is currently in clinical development for the treatment of chronic pain conditions. This trial focuses on the clinical pharmacokinetic (PK) properties of cebranopadol after oral single- and multiple-dose administration.

Methods The basic PK properties of cebranopadol were assessed by means of noncompartmental methods in six phase I clinical trials in healthy subjects and patients. A population PK analysis included two further phase I and six phase II clinical trials.
\end{abstract}

Elke Kleideiter

elke.kleideiter@grunenthal.com

1 Data Sciences-Clinical Pharmacology, Grünenthal GmbH, Zieglerstrasse 6, 52078 Aachen, Germany

2 Data Sciences-Pharmacometrics, Grünenthal GmbH, Aachen, Germany

3 Data Sciences-Biostatistics, Grünenthal GmbH, Aachen, Germany

4 Preclinical Drug Development-Pharmacokinetics, Grünenthal $\mathrm{GmbH}$, Aachen, Germany
Results After oral administration of the immediate-release (IR) formulation, cebranopadol is characterized by a late time to reach maximum plasma concentration $\left[C_{\max }\right]$ (4-6 h), a long half-value duration [HVD] (14-15 h), and a terminal phase half-life in the range of $62-96 \mathrm{~h}$. After multiple once-daily dosing in patients, an operational halflife (the dosing interval resulting in an accumulation factor [AF] of 2) of $24 \mathrm{~h}$ was found to be the relevant factor to describe the multiple-dose PKs of cebranopadol. The time to reach steady state was approximately 2 weeks, the AF was approximately 2 , and peak-trough fluctuation (PTF) was low (70-80\%). Dose proportionality at steady state was shown for a broad dose range of cebranopadol 200-1600 $\mu \mathrm{g}$. A two-compartment disposition model with two lagged transition compartments and a first-order elimination process best describes cebranopadol data in healthy subjects and patients after single- and multipledose administration.

Conclusions Cebranopadol formulated as an IR product can be used as a once-daily formulation; it reaches $C_{\max }$ after only 4-6 h, and has a long HVD and a low PTF. Therefore, from a PK perspective, cebranopadol is an attractive treatment option for patients with chronic pain. 


\section{Key Points}

This trial describes the key pharmacokinetic (PK) characteristics of an oral immediate-release formulation of cebranopadol evaluated in clinical trials and by a population PK analysis. Cebranopadol reaches maximum plasma concentrations after 4-6 h and has a long half-value duration of 14-15 h. With a dosing interval of $24 \mathrm{~h}$, cebranopadol achieves steady state within 2 weeks, accumulates twofold and shows a fluctuation of 70-80\%. Multiple-dose PKs of cebranopadol are predictable from a single dose.

Development of a cebranopadol extended-release formulation may not be required since the current product shows the PK properties of such a formulation. Based on the PK parameters described above, once-daily dosing is feasible, providing stable plasma concentrations and a consistent analgesic effect over a dosing interval.

In the population PK model, absorption and elimination were best described by linear processes confirming the overall linear behaviour of the PKs of cebranopadol across healthy populations and disease indications.

\section{Introduction}

Opioids represent effective analgesics with a broad spectrum and are used in acute and chronic pain conditions [1]. In clinical practice, extended-release (ER) opioids are used more often for the treatment of moderate-to-severe chronic pain in noncancer patients [2]. Despite the clinical benefits of these strong analgesics that act via $\mu$-opioid peptide (MOP) receptor agonism, concerns have been expressed about the safety of long-term opioid administration. Problems associated with long-term opioid treatment include adverse effects, development of tolerance to the analgesic effect, addiction, and drug diversion [3].

The nociceptin/orphanin FQ peptide (NOP) receptor has been classified as a subcategory of the opioid receptor family with very low affinity for classical opioid receptor ligands [4]. In nonhuman primate pain models of acute and inflammatory pain, selective NOP receptor agonists showed potent and efficacious analgesia without typical opioid-related side effects [5]. Thus, selective NOP, as well as bifunctional NOP/MOP, receptor agonists may hold potential for clinical use as analgesics [5].
Cebranopadol is a novel, potent, first-in-class analgesic acting as a NOP and opioid peptide receptor agonist with central analgesic activity. It binds with high affinity (subnanomolar to nanomolar range) to NOP and opioid receptors. Human receptor binding affinities are high and similar for NOP and MOP receptors, lower for $\kappa$-opioid receptors (partial agonist), and even lower for $\delta$-opioid receptors [6]. The NOP and opioid receptor agonism may potentially render cebranopadol a potent analgesic with an improved safety profile and a low abuse potential.

Cebranopadol is currently in clinical development for the treatment of various chronic pain conditions and is formulated as an immediate-release (IR) product for oral use. During clinical development, the basic pharmacokinetic (PK) properties of cebranopadol after oral single- and multiple-dose administration were investigated by means of noncompartmental methods in clinical trials in healthy subjects and patients with chronic pain conditions, and by population PK analysis.

This trial focuses on the description of the basic PK properties obtained from five phase I clinical trials in healthy subjects and one phase Ib clinical trial in patients with chronic low back pain (cLBP). A population PK analysis included two additional phase I clinical trials in healthy subjects and six phase II clinical trials in patients. All clinical trials were conducted in accordance with Good Clinical Practice (GCP), local laws, the ethical principles that have their origin in the Declaration of Helsinki, and with the approval of the appropriate local Ethics Committees. Informed consent was obtained from all individual subjects included in the trials.

\section{Methods}

\subsection{Trial Population}

An overview of the selected trials, including the trial population, used for assessment of the basic PK properties is shown in Table 1.

\subsection{Pharmacokinetic (PK) and Analytical Methods}

Blood samples for subsequent bioanalysis in trials 1-6 were collected using either K2-EDTA or lithium heparin as the anticoagulant. These samples were collected predose and at defined time points after administration of the trial medication postdose (see Table 3 for sampling times). Plasma samples from trials 1-6 were analysed in two different laboratories (Grünenthal $\mathrm{GmbH}$, Aachen, Germany, and Keystone Bioanalytical Inc., North Wales, PA, USA) using fully validated assays. After liquid/liquid extraction of the samples, cebranopadol was quantified using reverse- 
Table 1 Overview of the relevant trials used for assessment of the main clinical pharmacokinetic properties of cebranopadol

\begin{tabular}{|c|c|c|c|}
\hline Trial $^{\mathrm{a}}$ & $\begin{array}{l}\text { Population, no. of subjects } \\
\text { who received at least one } \\
\text { dose of cebranopadol (no. } \\
\text { of males/females) }\end{array}$ & Key eligibility criteria & $\begin{array}{l}\text { Cebranopadol dose regimen and route } \\
\text { of administration }\end{array}$ \\
\hline
\end{tabular}

Trial 1 (phase I trial)

Relative bioavailability trial

(EudraCT No. 2010-022004-53)

Trial 2 (phase I trial)

Mass balance and absolute bioavailability trial (EudraCT

No. 2008-000659-92)

Trial 3 (phase I trial)

Relative bioavailability trial

(EudraCT No. 2010-019021-34)

Healthy subjects, $24(24 / 0)$

Trial 4 (phase Ib trial)

Multiple-dose escalation trial in cLBP patients $^{\mathrm{c}}$

Healthy subjects, $24(24 / 0)$

Healthy subjects, $12(12 / 0)$
Healthy subjects, aged 18-45 years, BMI between 20 and $27 \mathrm{~kg} / \mathrm{m}^{2}$

Healthy subjects, aged $18-55$ years, BMI between 20 and $28 \mathrm{~kg} / \mathrm{m}^{2}$

Single oral dose of cebranopadol $200 \mu \mathrm{g}$ (film-coated tablets) and $400 \mu \mathrm{g}$ (oral solution and filmcoated tablet), fasted conditions ${ }^{\mathrm{b}}$

Single oral dose of cebranopadol $400 \mu \mathrm{g}$ (oral solution) followed by a single oral dose of $1 \mu \mathrm{g}{ }^{14} \mathrm{C}$ radiolabelled cebranopadol (oral solution), fasted conditions ${ }^{\mathrm{b}}$; single oral dose of cebranopadol $400 \mu \mathrm{g}$ (oral solution), fasted conditions, $4 \mathrm{~h}$ prior to an intravenous dose of $1 \mu \mathrm{g}{ }^{14} \mathrm{C}$-radiolabelled cebranopadol as an infusion over $30 \mathrm{~min}$

Healthy subjects, aged $18-55$ years, BMI between 20 and $28 \mathrm{~kg} / \mathrm{m}^{2}$

cLBP without a neuropathic component that has been present, by history, for $\geq 3$ months, and a pain DETECT score of $\leq 12$.

A pain intensity score of $\geq 4$ on the 11-point NRS at screening, and a 3-day mean daily average pain intensity score of $\geq 4$ on the 11-point NRS collected during the 3 consecutive days of the baseline period without the use of rescue medication
Single oral dose of cebranopadol $200 \mu \mathrm{g}$ (liquid-filled capsules) and $400 \mu \mathrm{g}$ (oral solution and liquidfilled capsule), fasted conditions ${ }^{\mathrm{b}}$

Cohort $1(n=11,5 \mathrm{M} / 6 \mathrm{~F})$ :

Multiple oral doses of cebranopadol $800 \mu \mathrm{g}$ qd from days 23 to 36 (with dose-escalation steps of $200 \mu \mathrm{g}$ qd from days 1 to 14 , and 400-600 $\mu \mathrm{g}$ qd from days 15 to 22 ), fed conditions $^{\mathrm{d}}$

Cohort $2(n=12,6 \mathrm{M} / 6 \mathrm{~F})$ :

Multiple oral doses of cebranopadol $1200 \mu \mathrm{g}$ qd from days 27 to 40 (with dose-escalation steps of $400 \mu \mathrm{g}$ qd on days $1-14$, and $600-800-1000 \mu \mathrm{g}$ from days 15 to 26), fed conditions ${ }^{\mathrm{d}}$

Cohort 3 ( $n=12,10 \mathrm{M} / 2 \mathrm{~F})$ :

Multiple oral doses of cebranopadol $1600 \mu \mathrm{g}$ qd from days 16 to 29 (with dose-escalation steps of 200-400-600-900-1300 $\mu \mathrm{g}$ qd from days 1 to 15 ), fed conditions ${ }^{\mathrm{d}}$

Cebranopadol was administered as film-coated tablets in the three cohorts 
Table 1 continued

\begin{tabular}{|c|c|c|c|}
\hline Trial $^{\mathrm{a}}$ & $\begin{array}{l}\text { Population, no. of subjects } \\
\text { who received at least one } \\
\text { dose of cebranopadol (no. } \\
\text { of males/females) }\end{array}$ & Key eligibility criteria & $\begin{array}{l}\text { Cebranopadol dose regimen and route } \\
\text { of administration }\end{array}$ \\
\hline \multicolumn{4}{|l|}{ Trial 5 (phase I trial) } \\
\hline $\begin{array}{l}\text { Multiple-dose escalation trial in } \\
\text { healthy subjects evaluating the } \\
\text { effects of cebranopadol on } \\
\text { cardiac repolarization }^{c}\end{array}$ & $\begin{array}{l}\text { Healthy subjects, } \\
117(63 / 54)\end{array}$ & $\begin{array}{l}\text { Healthy subjects, aged } 18-45 \text { years, } \\
\text { BMI } \geq 18 \mathrm{~kg} / \mathrm{m}^{2} \text { and } \leq 30 \mathrm{~kg} / \mathrm{m}^{2}\end{array}$ & $\begin{array}{l}\text { Group } 1 \text { ( } n=64,34 \mathrm{M} / 30 \mathrm{~F} \text { ): } \\
\text { Multiple oral doses of cebranopadol } \\
1600 \mu \mathrm{g} \text { qd from days } 16 \text { to } 29 \\
\text { (with dose-escalation steps of } \\
200-400-600 \mu \mathrm{g} \text { qd from days } 1 \text { to } \\
9 \text { and } 900-1300 \mu \mathrm{g} \text { qd from days } 10 \\
\text { to } 15 \text { ), fasted conditions on days } 1 \\
\text { and } 29 \text {, fed conditions }{ }^{\mathrm{d}} \text { on all other } \\
\text { dosing days } \\
\text { Group } 2 \text { ( } n=53 ; 29 \mathrm{M} / 24 \mathrm{~F} \text { ): } \\
\text { Multiple oral doses of cebranopadol } \\
600 \mu \mathrm{g} \text { qd from days } 16 \text { to } 29 \text { (with } \\
\text { dose-escalation steps of } 200-400 \mu \mathrm{g} \\
\text { qd from days } 10 \text { to } 15 \text { ), fasted } \\
\text { conditions on days } 1 \text { and } 29 \text {, fed } \\
\text { conditions }{ }^{\mathrm{d}} \text { on all other dosing days } \\
\text { In both groups cebranopadol was } \\
\text { administered as encapsulated tablets } \\
\text { (i.e. capsules containing } \\
\text { cebranopadol film-coated tablets) }\end{array}$ \\
\hline \multicolumn{4}{|l|}{ Trial 6 (phase I trial) } \\
\hline $\begin{array}{l}\text { First-in-man dose-escalation trial } \\
\text { with exploration of food and sex } \\
\text { effect on pharmacokinetics } \\
\text { (EudraCT No. 2006-005869-18) }\end{array}$ & $\begin{array}{l}\text { Dose-escalation part: } \\
\text { healthy subjects, } \\
20(20 / 0) \\
\text { Food effect part: } \\
\text { healthy subjects, } \\
6(0 / 6)\end{array}$ & $\begin{array}{l}\text { Healthy subjects, aged } 18-45 \text { years, } \\
\text { BMI between } 20 \text { and } 27 \mathrm{~kg} / \mathrm{m}^{2} \\
\text { inclusive }\end{array}$ & $\begin{array}{l}\text { Dose-escalation part: Single oral dose } \\
\text { of cebranopadol } 0.8,4,16,48,100 \text {, } \\
200,400,600 \text { and } 800 \mu \mathrm{g} \text { (oral } \\
\text { solution), fasted conditions }{ }^{\mathrm{b}} \\
\text { Food effect part: Single oral dose of } \\
\text { cebranopadol } 400 \mu \mathrm{g} \text { (oral } \\
\text { solution), fasted }^{\mathrm{b}} \text { and fed } \mathrm{e}^{\mathrm{e}} \\
\text { conditions }^{\text {condions }}\end{array}$ \\
\hline
\end{tabular}

${ }^{a}$ Owing to the focus of this paper, the trials are not necessarily presented in chronological order of the trial conduct

b No calorie intake for at least $10 \mathrm{~h}$ predose and $4 \mathrm{~h}$ postdose

c Trial has no public clinical trial registration reference identification

d Standardized breakfast in the course of the multiple-dose trial

e Standardized continental breakfast to investigate food effect

$B M I$ body mass index, $c L B P$ chronic low back pain, EudraCT European Union Drug Regulating Authorities Clinical Trials, $F$ females, $M$ males, $N R S$ numeric rating scale, $q d$ once daily

phase liquid chromatography-tandem mass spectrometry methods, with $\mathrm{D}_{5}$-cebranopadol as the internal standard. The ${ }^{14} \mathrm{C}$-radiolabelled cebranopadol in plasma samples from trial 2 was determined by accelerator mass spectrometry. Assays were conducted at Vitalea Science, Davis, CA, USA.

Noncompartmental PK evaluation was performed using the Grünenthal software package MODUNA (for the single-dose trials) or WinNonlin (for the multiple-dose trials). The PK parameters thus derived included:

- Maximum plasma concentration ( $C_{\max }$ after single dose or $C_{\max , s s}$ at steady state);
- Time to $C_{\max }\left(t_{\max }\right)$;

- Area under the plasma concentration-time curve (AUC) from time zero to the last time with a quantifiable concentration $\left(\mathrm{AUC}_{\mathrm{t}}\right), \mathrm{AUC}$ from time zero to $72 \mathrm{~h}$ postdose $\left(\mathrm{AUC}_{72}\right)$, AUC for one 24-h dosing interval at steady state $\left(\mathrm{AUC}_{\tau, \mathrm{ss}}\right)$;

- Half-life associated with the terminal phase $\left(t_{1 / 2, z}\right)$;

- Total plasma clearance (CL), apparent oral CL (CL/f);

- Apparent volume of distribution during the terminal phase $\left(V_{\mathrm{z}}\right)$, or $V_{\mathrm{z}}$ after oral administration $\left(V_{\mathrm{z}} / f\right)$;

- Absolute bioavailability $(f)$; 
- Mean residence time (MRT) calculated as the area under the first moment curve/AUC (area to infinite time);

- Half-value duration (HVD) defined as the time interval during which cebranopadol plasma concentrations were above $50 \%$ of $C_{\max }$;

- Peak-trough fluctuation (PTF) calculated as $C_{\text {max,ss }}-$ $C_{\text {min,ss }} / C_{\text {av,ss }}$ (where $C_{\text {min,ss }}$ is the minimum plasma concentration during a dosing interval and $C_{\mathrm{av}, \mathrm{ss}}$ is the average steady-state plasma concentration within a dosing interval)

\subsection{Trial Designs}

Owing to the focus of this trial, the trials are not necessarily presented in chronological order of the trial conduct.

\subsubsection{Relative Bioavailability Trial in Healthy Subjects Comparing a Film-Coated Tablet Formulation with an Oral Solution (Trial 1)}

A randomized, single-centre, open-label, three-way crossover, single-dose, phase I clinical trial in 24 healthy male subjects was conducted to compare two different dose strengths of a cebranopadol tablet formulation with a cebranopadol oral solution in the fasted state. Primary cebranopadol PK parameters were $C_{\max }, \mathrm{AUC}_{72}$ and $\mathrm{AUC}_{\mathrm{t}}$. Additional PK parameters evaluated included $t_{\max }, t_{1 / 2, \mathrm{Z}}$, MRT, HVD, CL/ $f$ and $V_{\mathrm{z}} / f$. All subjects who had evaluable PKs in all three periods were included in the statistical analysis of the main PK parameters.

\subsubsection{Mass Balance and Absolute Bioavailability Trial in Healthy Subjects (Trial 2)}

A phase I, nonrandomized, single-centre, open-label, noncontrolled trial was performed in 12 healthy subjects to determine the excretion balance, metabolite profile, and absolute oral bioavailability of cebranopadol. A parallel design with two groups was adopted: Group 1 (six subjects) received a single oral dose of cebranopadol $400 \mu \mathrm{g}$ plus ${ }^{14} \mathrm{C}$-radiolabelled cebranopadol $1 \mu \mathrm{g}$, and Group 2 (six subjects) received a single oral dose of cebranopadol 400 $\mu \mathrm{g}$ plus an intravenous dose of ${ }^{14} \mathrm{C}$-radiolabelled cebranopadol $1 \mu \mathrm{g}$. In both groups, cebranopadol was administered in the fasted state. PK parameters reported here include $f, \mathrm{CL}$ and $V_{\mathrm{z}}$ after intravenous administration. Descriptive statistics for plasma concentration data considered only subjects who received the intended dose of cebranopadol and provided evaluable PK parameters.

\subsubsection{Relative Bioavailability Trial in Healthy Subjects Comparing a Liquid-Filled Capsule Formulation with an Oral Solution (Trial 3)}

A randomized, single-centre, open-label, three-way crossover, single-dose, phase I clinical trial in 24 healthy male subjects was conducted to compare the PKs of a cebranopadol liquid-filled capsule formulation in two dose strengths with a cebranopadol oral solution in the fasted state. Operational half-life $\left(t_{1 / 2, \mathrm{op}}\right)$, accumulation factor (AF) and time to reach steady state $\left(t_{97 \%, \mathrm{ss}}\right.$, time to reach $97 \%$ of $C_{\text {max,ss }}$ ) were estimated in addition to the standard PK parameters. The $t_{1 / 2, \text { op }}$ is defined as the dosing interval at steady state, such that the maximum concentration is twice the maximum concentration found for the first dose [7]. Single-dose profiles were evaluated with a two-compartmental model using WinNonlin, while steady-state data after different dosing intervals were derived from the resulting parameters using the simulation mode of WinNonlin. The predicted concentration profiles were analysed with noncompartmental methods. All subjects who had evaluable PKs in all three periods were included in the statistical analysis of the main PK parameters.

\subsubsection{A Multiple-Dose Escalation Trial in Patients with Chronic Low Back Pain (Trial 4)}

A single-centre, randomized, in-patient, double-blind, placebo-controlled, multiple-cohort (sequential), dose-escalation trial was performed in patients with cLBP to assess the safety, tolerability, and PKs of multiple escalating oral doses of cebranopadol, and to identify the maximum tolerated dose. Details regarding the cebranopadol dosage regimen are shown in Table 1. The PK parameters obtained after multiple dosing, such as $C_{\mathrm{max}, \mathrm{ss}}, C_{\mathrm{av}}, C_{\mathrm{min}, \mathrm{ss}}, \mathrm{AUC}_{\tau, \mathrm{ss}}$, $t_{\max }, t_{1 / 2, \mathrm{op}}$, AF and PTF are reported.

Descriptive statistics were provided for all PK parameters by dose level in each cohort for all patients with evaluable PK parameters. Dose proportionality of the PK parameters $C_{\mathrm{max}, \mathrm{ss}}, C_{\mathrm{min}, \mathrm{ss}}$ and $\mathrm{AUC}_{\tau, \mathrm{ss}}(\tau=24$ h) of cebranopadol was tested using linear regression analysis. Time to reach steady state was evaluated by calculation of geometric mean ratios with $90 \%$ confidence intervals (CIs) of adjacent trough plasma concentrations. Steady state was reached when the ratio of the geometric mean predose plasma drug concentration on day $X$ and the geometric mean predose plasma drug concentration on day $X-1$ fell within the limits of $80-125 \%$. 


\subsubsection{A Multiple-Dose Escalation Trial in Healthy Subjects (Trial 5)}

A single-centre, randomized (stratified by sex), doubleblind, placebo- and positive-controlled, parallel-group, multiple-dose trial to assess the effects of multiple therapeutic $(600 \mu \mathrm{g} /$ day $)$ and supratherapeutic $(1600 \mu \mathrm{g} /$ day $)$ doses of cebranopadol on cardiac repolarization was performed in healthy subjects. All treatments were applied once daily. The trial included four treatment groups, of which two (Groups 1 and 2) are reported here. Sixty-four subjects in Group 1 received cebranopadol $1600 \mu \mathrm{g} /$ day from days 16 to 29 (with dose-escalation steps from days 1 to 15) (see Table 1). Fifty-three subjects in Group 2 received cebranopadol $600 \mu \mathrm{g} /$ day from days 16 to 29 (with dose-escalation steps from days 10 to 15) [see Table 1]. PK parameters reported here are $C_{\mathrm{max}, \mathrm{ss}}, t_{\mathrm{max}}$, $\operatorname{AUC}_{\tau, \mathrm{ss}}(\tau=24 \mathrm{~h})$ and PTF. Descriptive statistics were provided by dose for all $\mathrm{PK}$ parameters for subjects with evaluable $C_{\mathrm{max}, \mathrm{ss}}$ and $\mathrm{AUC}_{\tau, \mathrm{ss}}$.

\subsubsection{First-in-Man Dose-Escalation Trial with Exploration of the Effect of Food and Sex on the PKs of Cebranopadol in Healthy Subjects (Trial 6)}

A single-centre, dose-escalation trial following a randomized, double-blind, placebo-controlled design was performed in healthy male subjects to evaluate the safety, tolerability, PKs, and pharmacodynamics of cebranopadol. Single oral doses of cebranopadol (dose steps of $0.8 \mu \mathrm{g}$ up to $800 \mu \mathrm{g}$ ) or placebo were administered in the fasted state to 21 healthy subjects (in two parallel cohorts, Groups 1 and 2). Administration to individual subjects was separated by at least 2 weeks of washout. In addition, following the dose escalation, eight subjects (Group 4; a total of six subjects in Groups 1 and 2 were enrolled in this group) received a single oral dose of cebranopadol $600 \mu \mathrm{g}$ or placebo to better characterize the dose response curve and to increase the robustness and predictability of the obtained PK data of cebranopadol.

Following dose escalation, nine healthy female subjects (Group 3) received a single oral dose of cebranopadol $400 \mu \mathrm{g}$ or placebo in the fasted and fed (continental breakfast) states to explore the influence of food on the PKs of cebranopadol.

The influence of food on the main PK parameters was investigated by means of analysis of variance (ANOVA) on the $\log (\ln )$-transformed PK parameters of female subjects, and included fed/fasted status as the fixed effect and subject as the random effect. Parametric point estimates and 90\% CIs were calculated for the ratios between the treatment periods using least square means. Subjects for whom all planned treatment periods were available and the PK parameters were evaluable were included in the analysis.

To evaluate the effect of sex on the PKs of cebranopadol, the concentration profile characteristics of cebranopadol in female and male subjects after single oral administration of cebranopadol $400 \mu \mathrm{g}$ in the fasted state were compared. An ANOVA was also conducted, including sex as the fixed effect in the model.

\subsection{Population PK Analysis}

A population PK analysis of cebranopadol using data from phase I and II trials (Tables 1,2) was performed to develop and validate a population PK model able to comprehensively describe the PKs of cebranopadol in both healthy subjects and patients, and to identify the potential relationships between PK parameters and covariates.

Blood samples for quantification of cebranopadol in plasma were collected, as indicated in Table 3, and were used for the PK modelling.

\subsubsection{Development of the Structural and Statistical PK Models}

The log (ln)-transformed cebranopadol concentrations were treated as dependent variables in this investigation. Linear and nonlinear PK models (e.g. Michaelis-Menten kinetics) were tested, and multiple compartmental distribution models were examined. Model-building criteria included the objective function value (OFV), the standard error of estimates of the parameters and standard goodness-of-fit plots.

All parameters were assumed to be log-normally distributed, as shown in Eq. (1):

$P_{i}=\hat{P} \exp \left(\eta_{P_{i}}\right)$,

where $P_{i}$ is the estimated parameter value for individual $i$, $\hat{P}$ is the typical population value (geometric mean) of the parameter, and $\eta_{P i}$ is the individual-specific interindividual random effects for individual $i$ and parameter $P$. The $\eta_{P i}$ is assumed to be normally distributed with a mean of zero and variance of $\omega^{2}$. A covariance matrix is defined by the interindividual covariance matrix $\Omega$.

The residual error model was described by an additive error model, as shown in Eq. (2):

$C_{i j}=\hat{C}_{i j}+\varepsilon_{a i j}$,

where $C_{i j}$ is the $\log (\ln )$-transformed $j$ th measured observation in individual $i, \hat{C}_{i j}$ is the $\log (\ln )$-transformed $j$ th model-predicted value in individual $i$, and $\varepsilon_{a i j}$ is the additive residual random error for individual $i$ and measurement $j$ and is assumed to be normally distributed with a mean of zero and variance of $\sigma^{2}$. 


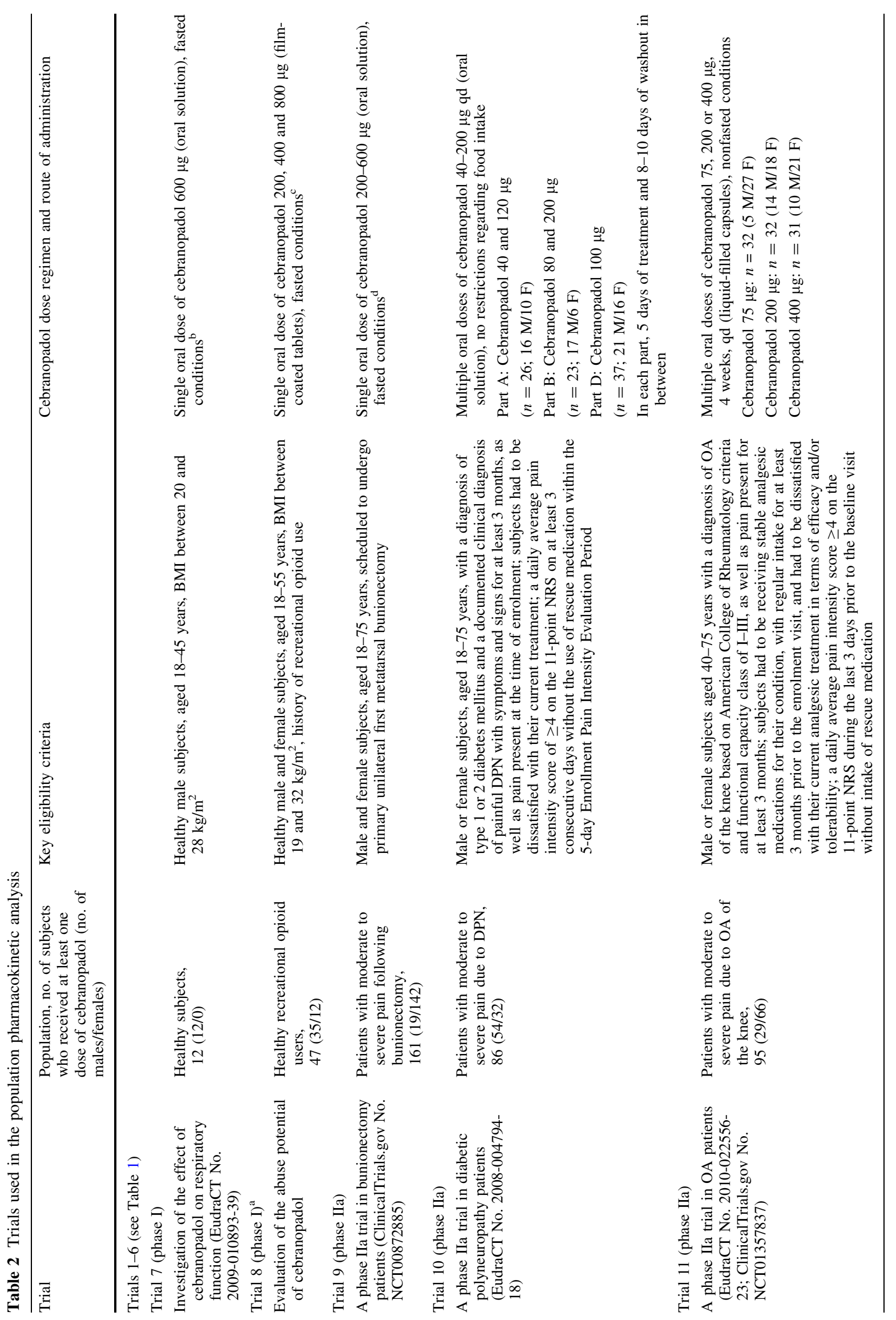




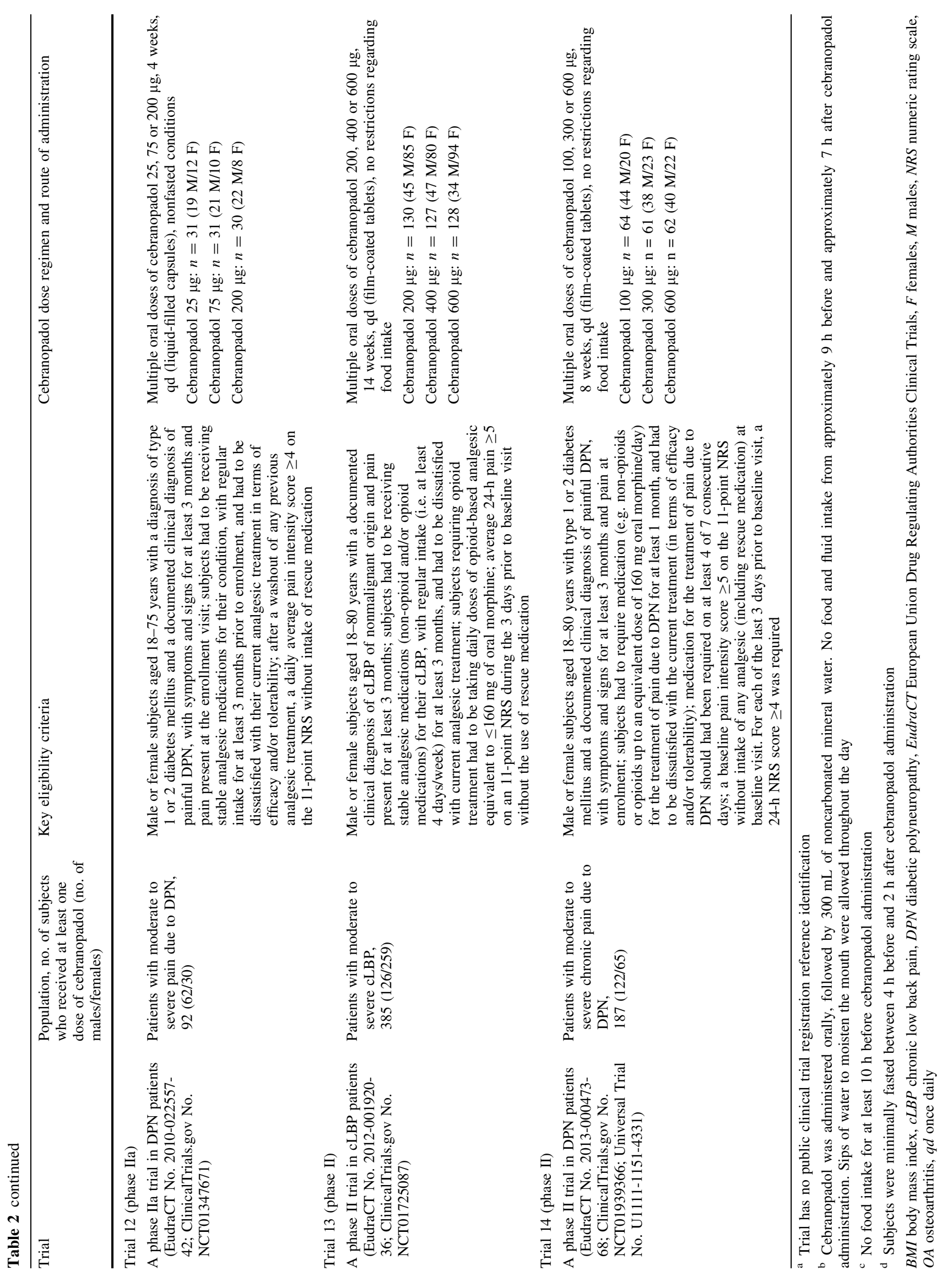


Table 3 Summary of the postdose blood sampling schemes used in the trials

\begin{tabular}{|c|c|c|c|}
\hline Trial & $\begin{array}{l}\text { No. of } \\
\text { quantifiable } \\
\text { samples }\end{array}$ & $\begin{array}{l}\text { No. of } \\
\text { samples BQL }\end{array}$ & Postdose nominal sampling time ${ }^{\mathrm{a}}$ \\
\hline \multicolumn{4}{|l|}{ Phase I } \\
\hline Trial 1 & 845 & 320 & $\begin{array}{l}0.03,0.17,0.42,0.75,1.25,2.08,3.5,6,10,17,29,48,72,144,240 \text { and } 336 \mathrm{~h} \text { postdose for } \\
\text { each treatment period }\end{array}$ \\
\hline Trial 2 & 213 & 63 & $\begin{array}{l}0.25,0.5,0.75,1,1.5,2,3,3.92,4,4.08,04.25,04.47,04.58,4.75,5.25,6,7,8,9,9.5,11.5,12 \text {, } \\
\quad 14,16,24,36,48,72,96,120 \text { and } 144 \mathrm{~h} \text { postdose }\end{array}$ \\
\hline Trial 3 & 896 & 304 & $\begin{array}{l}0.03,0.17,0.42,0.75,1.25,2.08,3.5,6,10,17,29,48,72,144,240 \text { and } 336 \mathrm{~h} \text { postdose for } \\
\text { each treatment period }\end{array}$ \\
\hline Trial 4 & 1482 & 24 & $\begin{array}{l}0.5,1,2,4,5,6,7,8,10 \text { and } 14 \mathrm{~h} \text { postdose on day } 1 ; 0 \mathrm{~h} \text { on days } 2,4,6,8 \text { and } 10-13 \text { on each } \\
\text { day (prior to IMP administration); } 0 \mathrm{~h} \text { (prior to IMP administration) and } 0.5,1,2,4,5,6,7,8 \text {, } \\
10 \text { and } 14 \mathrm{~h} \text { postdose on day } 14 ; 0 \mathrm{~h} \text { (prior to IMP administration) on days } 15,17,19,21,23 \text {, } \\
25,27,29,31,33-35 ; 0 \mathrm{~h} \text { (prior to IMP administration) and } 0.5,1,2,4,5,6,7,8,10,14,24 \text {, } \\
36,48,72,96 \text { and } 120 \mathrm{~h} \text { postdose on day } 36\end{array}$ \\
\hline Trial 5 & 2764 & 0 & $\begin{array}{l}0.5,1,2,3,4,6,8,14 \text { and } 24 \mathrm{~h} \text { postdose on days } 1 \text { and } 29 \text {, and } 0.5,1,2,3 \text {, } \\
4,6,8,14,24,48,72 \text { and } 96 \mathrm{~h} \text { postdose on day } 30\end{array}$ \\
\hline Trial 6 & 410 & $553^{\mathrm{b}}$ & $0.5,1,1.5,2,3,4,6,8,10,12,14,24,36,48$ and $72 \mathrm{~h}$ postdose \\
\hline Trial 7 & 146 & 33 & $0.25,1,1.5,2,3,4,5,6,8,10,12,18,24$, and $32 \mathrm{~h}$ postdose \\
\hline Trial 8 & 1552 & 92 & $0.5,1,1.5,2,3,4,4.5,5,5.5,6,8,10,12,24,36,56 \mathrm{~h}$ postdose for each treatment period \\
\hline
\end{tabular}

Phase IIa

\begin{tabular}{|c|c|c|c|}
\hline Trial 9 & 628 & 8 & $\begin{array}{l}\text { Between } 0.5 \text { and } 3,3 \text { and } 8,8 \text { and } 16 \text {, and } 16 \text { and } 36 \mathrm{~h} \text { postdose (with at least } 2,5 \text { and } 8 \mathrm{~h} \\
\text { between samples, respectively) }\end{array}$ \\
\hline Trial 10 & 998 & 91 & $\begin{array}{l}\text { Between } 0.5 \text { and } 3 \mathrm{~h} \text { after the first dose on day } 1 \text {; between } 3 \text { and } 8 \mathrm{~h} \text { after the third dose on day } \\
3 \text {; predose and one sample in each of the time intervals of } 0.5-3 \mathrm{~h}, 3-8 \mathrm{~h}, 8-16 \mathrm{~h}, 16-36 \mathrm{~h} \text { on } \\
\text { day } 5\end{array}$ \\
\hline Trial 11 & 936 & 9 & $\begin{array}{l}\text { Between } 1 \text { and } 2 \mathrm{~h} \text { and } 4 \text { and } 6 \mathrm{~h} \text { postdose at visit } 3 \text {; two samples at visits } 4,5 \text { and } 6 \text { : one } \\
\text { sample predose and one sample } 4-6 \mathrm{~h} \text { postdose; three samples at visit } 7 \text { : one sample predose } \\
\text { and one sample } 4-6 \mathrm{~h} \text { postdose; one sample } 24 \mathrm{~h} \text { after last IMP intake; one sample at visit } 8\end{array}$ \\
\hline Trial 12 & 961 & 46 & $\begin{array}{l}\text { Between } 1 \text { and } 2 \mathrm{~h} \text { and } 4 \text { and } 6 \mathrm{~h} \text { postdose on day } 1 \text {; two samples at each of the treatment visits } \\
\text { at weeks } 1,2 \text { and } 3 \text { : one sample predose and one sample between } 4 \text { and } 6 \mathrm{~h} \text { postdose; three } \\
\text { samples at the final visit: one sample predose and one sample } 4-6 \mathrm{~h} \text { after postdose; one } \\
\text { sample } 24 \mathrm{~h} \text { after last intake of the IMP; one sample at the follow-up visit }\end{array}$ \\
\hline
\end{tabular}

Phase II

Trial $131121 \quad 75 \quad$ One sample between 3 and $7 \mathrm{~h}$ postdose at visits 5, 6, 7 and 9; one sample at the follow-up visit Trial $14553 \quad 65 \quad$ One sample between 3 and $7 \mathrm{~h}$ postdose at visits 3, 5 and 6; one sample at the follow-up visit

${ }^{a}$ For modelling purposes, the real sampling time was used

${ }^{\mathrm{b}}$ Doses of cebranopadol up to $48 \mu \mathrm{g}$ did not result in measurable plasma concentrations. The number of samples BQL decreased with increasing dose

$B Q L$ below the lower limit of quantification, IMP investigational medicinal product

Alternative error models such as proportional and combined error models were also tested during model development.

Covariates describing known physiologic effects on PK parameters were evaluated during the analysis. For example, if a parameter such as CL was correlated with body weight (continuous covariate) according to a power function, this relationship was included in the model, as described in Eq. (3):
$\mathrm{TVP}=\theta_{\mathrm{TVP}}\left(\frac{\mathrm{WT}_{i}}{\mathrm{WT}_{\text {ref }}}\right)^{\theta_{\exp }}$

where the typical value of a model parameter (TVP) is described as a function of individual body weight $\left(\mathrm{WT}_{i}\right)$, normalized by a reference weight $\left(\mathrm{WT}_{\text {ref }}\right)$, i.e. $82 \mathrm{~kg}, \theta_{\mathrm{TVP}}$ is an estimated parameter describing the typical PK parameter value for an individual with weight equal to the reference weight, and $\theta_{\exp }$ is the exponent of the function 
describing the relationship between the estimated parameter and body weight.

For categorical covariates, e.g. patient population, a linear correlation was introduced, as described in Eq. (4):

$\mathrm{TVP}=\theta_{\mathrm{TVP}}\left(1+\theta_{\mathrm{LIN}}\right)$,

where $\theta_{\text {TVP }}$ is an estimated parameter describing the typical PK parameter value for a reference patient population, which is the most common category for the covariate, and $\theta_{\text {LIN }}$ is the linear coefficient between a different population and the reference population, which is the most common category for the covariate.

Continuous and categorical covariates were tested during the analysis. Covariate selection was performed by means of a forward inclusion and backward elimination procedure. Relevant demographic covariates were entered one by one into the population model (univariate analysis). After all significant covariates had been entered into the model (forward inclusion), each covariate was removed (backward elimination) one at a time. The model was run again and the objective function recorded. The likelihood ratio test was used to assess whether the difference in the objective function between the base model and the full (more complex) model was significant. The difference in $-2 \log$ of the likelihood between the base and the full model is approximately Chi-square distributed, with degrees of freedom equal to the difference in the number of parameters between the two hierarchical models. Owing to the exploratory nature of this investigation, for univariate analyses an additional parameter leading to a decrease in the objective function of 6.64 was considered significant $(p<0.01)$. During the final steps of the model building, only the covariates that resulted in a difference of objective function of $7.88(p<0.005)$ were kept in the final model. The forward inclusion and backward elimination steps were implemented using the Stepwise Covariate Model building tool of Pearl-speaks-NONMEM v3.6.2.

The following assumptions were applied:

- All concentrations below the lower limit of quantification (BLQ) were excluded from the analysis.

- Missing values $(<1 \%)$ for continuous covariates were replaced by the median value.

- Derived covariate creatinine $\mathrm{CL}(\mathrm{CrCl})$ was calculated from the observed data according to the CockcroftGault formula [8].

The final model was validated by means of a visual predictive check and bootstrap. Nonlinear mixed-effects modelling was performed in NONMEM version 7.2.

The individual impact of a selected number of significant covariates on cebranopadol exposure was investigated by simulations. Each simulation was performed by changing one covariate (tested value) at a time, while keeping the other covariates as the reference values. The covariate values to be tested were selected based on clinical and safety considerations. For each simulation, PK profiles from 1000 subjects were simulated based on a titration scheme of $100 \mu \mathrm{g}$ for 6 days, $200 \mu \mathrm{g}$ for 6 days and $400 \mu \mathrm{g}$ for 6 days to reach the cebranopadol target dose of $600 \mu \mathrm{g}$. Median values of maximum concentration at steady state $\left(C_{\max , s s}\right)$ and area under the curve at steady state $\left(\mathrm{AUC}_{\mathrm{ss}}\right)$ were calculated. The time to reach steady state was calculated as the time point when the AUC reaches $98 \%$ of the AUC at absolute steady state, e.g. maximum AUC value during a duration of 50 days.

\section{Results}

\subsection{Trial Participants}

Demographics and baseline characteristics of subjects in the six clinical trials (trials 1-6, Table 1) are summarized in Table 12.

\subsection{PK Characteristics of Cebranopadol Evaluated in Six Clinical Trials}

Selected results from the six phase I trials described in Sect. 2.3 are presented here to fully characterize the basic PK properties of cebranopadol. Owing to the PK focus of this trial, not all aspects of each trial (e.g. safety and tolerability) are discussed in the following sections.

\subsubsection{PKs of Cebranopadol After Single Oral Dose Administration in Healthy Subjects (Trial 1)}

The key PK characteristics of cebranopadol after single oral dosing were determined in the relative bioavailability trial comparing the $4 \times 50 \mu \mathrm{g}$ and $1 \times 400 \mu \mathrm{g}$ film-coated tablets with the oral solution (Table 1). Arithmetic mean plasma cebranopadol concentrations versus time following the first $72 \mathrm{~h}$ (the same time period as for the main PK parameter $\mathrm{AUC}_{72}$ ) after administration of the treatments are shown in Fig. 1. Descriptive statistics of the main PK parameters of cebranopadol, by treatment, are summarized in Table 4 .

In healthy subjects, the mean $t_{1 / 2, \mathrm{z}}$ ranged from 61.7 to $95.3 \mathrm{~h}$, and the HVD was estimated to be 14.0-15.3 h.

In this trial, the observed interindividual variability of both $C_{\max }$ and $\mathrm{AUC}_{72}$ was moderate, with coefficients of variation between 38.3 and $43.9 \%$, and 40.0 and $48.9 \%$, respectively.

\subsubsection{Absolute Bioavailability and PKs of Oral Cebranopadol Compared with an Intravenous Dose of Cebranopadol (Trial 2)}

Following intravenous administration of ${ }^{14} \mathrm{C}$-cebranopadol to healthy subjects in the mass balance trial (Table 1), the 


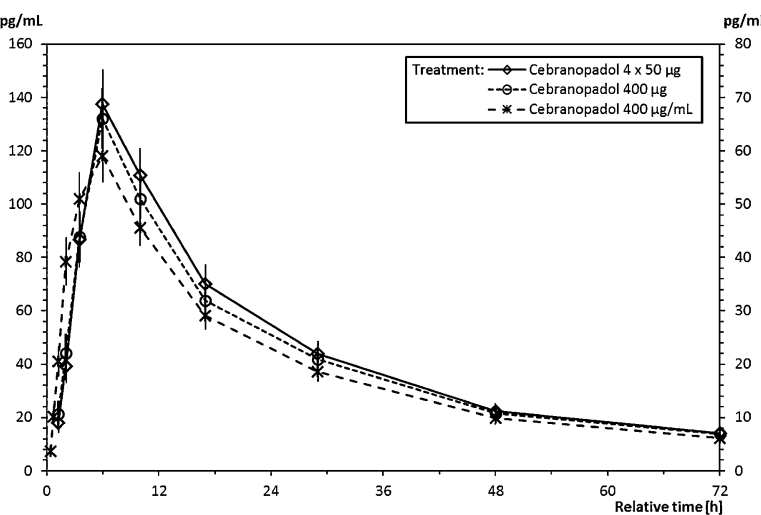

Fig. 1 Arithmetic mean cebranopadol concentrations in plasma versus time (h) within the first $72 \mathrm{~h}$ after administration (trial 1). The $200 \mu \mathrm{g}$ dose treatment (cebranopadol $4 \times 50 \mu \mathrm{g}$ ) is plotted using the right $y$-axis, and whiskers on the linear scale show the arithmetic mean \pm SEM. Cebranopadol $4 \times 50 \mu \mathrm{g}=$ cebranopadol $4 \times 50 \mu \mathrm{g}$ film-coated tablets; cebranopadol $400 \mu \mathrm{g}=$ cebranopadol $400 \mu \mathrm{g}$ film-coated tablet; cebranopadol $400 \mu \mathrm{g} / \mathrm{mL}=$ oral solution. SEM standard error of the mean

$V_{\mathrm{z}}$ for ${ }^{14} \mathrm{C}$-radiolabelled cebranopadol was $1832 \pm 467 \mathrm{~L}$ (mean \pm standard deviation $[\mathrm{SD}]$ ) and the $\mathrm{CL}$ was $50.4 \pm 10.4 \mathrm{~L} / \mathrm{h}$ (mean $\pm \mathrm{SD}$ ) [data on file].

The mean oral bioavailability (fasted state) of cebranopadol was approximately $40 \%$, indicating a substantial first-pass metabolism. Comparison of the early exposure $\left(\mathrm{AUC}_{24}\right)$ with total radioactivity following oral and intravenous administrations in the pooled samples suggested that absorption of cebranopadol was complete (data on file).

\subsubsection{Prediction of Steady-State Concentrations Using Single-Dose PK Data of a Relative Bioavailability Trial (Trial 3)}

The single-dose PK data of the relative bioavailability trial comparing the cebranopadol liquid-filled capsules with the cebranopadol oral solution were also used to predict steady-state concentrations, time to reach steady state, and the AF.

Steady-state concentrations were predicted to be reached within approximately 14 days (variation between 13 and 15 days) with an AF of approximately 2, corresponding to a $t_{1 / 2, \text { op }}$ of approximately $24 \mathrm{~h}$ (Table 5).

\subsubsection{PKs of Cebranopadol After Multiple-Dose Administration in Patients with Chronic Low Back Pain (Trial 4)}

Following once-daily administration of cebranopadol up to $1600 \mu \mathrm{g} /$ day between 29 and 40 days to patients with cLBP (Table 1), the plasma concentrations of cebranopadol peaked between approximately 5 and $6.5 \mathrm{~h}$ (median data) postdose across all doses investigated (Tables 6 , 7).

Accumulation of cebranopadol following 14 days of daily 200 or $400 \mu \mathrm{g}$ doses was approximately twice that of a single dose, consistent with a $t_{1 / 2, \text { op }}$ of $24 \mathrm{~h}$ and in agreement with the value predicted in healthy subjects (see Sect. 3.2.3). Steady-state cebranopadol plasma concentrations were reached in most patients following 13 days of daily dosing.
Table 4 Descriptive statistics of PK parameters of cebranopadol by treatment after single-dose administration (trial 1)

\begin{tabular}{llll}
\hline Parameter (units) & \multicolumn{3}{l}{ Treatment } \\
\cline { 2 - 4 } & $4 \times 50 \mu \mathrm{g}$ tablets & $400 \mu \mathrm{g}$ tablet & $400 \mu \mathrm{g} / \mathrm{mL}$ oral solution \\
\hline$C_{\max }(\mathrm{pg} / \mathrm{mL})$ & $71.1 \pm 31.2$ & $135 \pm 52.5$ & $120 \pm 45.9$ \\
$\mathrm{AUC}_{\mathrm{t}}(\mathrm{pg} \mathrm{h} / \mathrm{mL})$ & $2139 \pm 1611$ & $4501 \pm 2658$ & $4148 \pm 2773$ \\
$\mathrm{AUC}_{72}(\mathrm{pg} \mathrm{h} / \mathrm{mL})$ & $1609 \pm 787$ & $3066 \pm 1225$ & $2861 \pm 1251$ \\
$t_{1 / 2, \mathrm{z}}(\mathrm{h})$ & $61.7 \pm 37.4$ & $84.7 \pm 27.8$ & $95.3 \pm 38.8$ \\
$t_{\max }(\mathrm{h})$ & $6.00(3.50-10.0)$ & $6.00(3.50-10.0)$ & $6.00(2.08-10.0)$ \\
$\mathrm{CL} / f(\mathrm{~L} / \mathrm{h})$ & $117 \pm 67.2$ & $102 \pm 50.6$ & $103 \pm 46.1$ \\
$V_{\mathrm{z}} / f(\mathrm{~L})$ & $7635 \pm 2513$ & $10842 \pm 2922$ & $12269 \pm 3967$ \\
$\mathrm{HVD}(\mathrm{h})$ & $14.3 \pm 3.49$ & $14.0 \pm 3.47$ & $15.3 \pm 3.58$ \\
MRT $(\mathrm{h})$ & $67.2 \pm 36.5$ & $85.2 \pm 29.4$ & $89.0 \pm 36.3$ \\
\hline
\end{tabular}

Data are expressed as arithmetic mean \pm standard deviation, except for $t_{\max }$, which is expressed as median (range)

Dependent on the PK parameter, 19, 21 or 22 subjects were included in the analysis

$A U C$ area under the plasma concentration-time curve, $A U C_{t}$ AUC from time zero to the last time with a quantifiable concentration, $A U C_{72}$ AUC from time zero to $72 \mathrm{~h}$ postdose, $C L / f$ apparent oral clearance, $C_{\max }$ maximum plasma concentration, $H V D$ half-value duration, $M R T$ mean residence time, $P K$ pharmacokinetic, $t_{1 / 2, z}$ half-life associated with the terminal phase, $t_{\max }$ time to $C_{\max }, V_{z} / f$ apparent volume of distribution during the terminal phase after oral administration 
Table 5 Descriptive statistics of pharmacokinetic parameters of cebranopadol by treatment (trial 3)

\begin{tabular}{llll}
\hline Parameter (units) & Treatment & & \\
\cline { 2 - 4 } & $4 \times 50 \mu \mathrm{g}$ capsules $(N=24)$ & $400 \mu \mathrm{g}$ capsule $(N=24)$ & $400 \mu \mathrm{g} / \mathrm{mL}$ oral solution $(N=24)$ \\
\hline$t_{1 / 2, \mathrm{op}}(\mathrm{h})^{\mathrm{b}}$ & $21.6 \pm 6.91^{\mathrm{a}}$ & $21.2 \pm 4.80$ & $23.8 \pm 5.91$ \\
$\mathrm{AF}^{\mathrm{b}}$ & $1.92 \pm 0.427$ & $1.85 \pm 0.256$ & $1.97 \pm 0.320^{\mathrm{a}}$ \\
$t_{97 \%, \mathrm{ss}}($ days) & $12.9 \pm 6.16$ & $12.8 \pm 4.26$ & $15.0 \pm 4.77$ \\
\hline
\end{tabular}

Data are expressed as arithmetic mean \pm standard deviation

a $n=23$

b Derived using compartmental methods $\left(t_{96.875 \%, s s}\right)$

$A F$ accumulation factor, $C_{\max , s s}$ maximum plasma concentration at steady state, $N$ total number of subjects, $n$ number of observations, $t_{1 / 2, o p}$ operational half-life, $t_{97 \%, s s}$ time to reach $97 \%$ of $C_{\max , s s}$ in case of daily dosing: $t$ of first sample with $C(t)>0.97 \times C_{\text {max,day }} 28$

Table 6 Descriptive statistics of pharmacokinetic parameters for cebranopadol (cohort 1) following single or multiple doses of cebranopadol (trial 4)

\begin{tabular}{|c|c|c|c|}
\hline \multirow[t]{2}{*}{ Parameter (units) } & \multicolumn{3}{|l|}{ Treatment } \\
\hline & $\begin{array}{l}200 \mu \mathrm{g} \text { SD (day } 1) \\
(n=11)\end{array}$ & $\begin{array}{l}200 \mu \mathrm{g} \text { SS (day } 14) \\
(n=11)\end{array}$ & $\begin{array}{l}800 \mu \mathrm{g} \text { SS (day } 36) \\
(n=11)\end{array}$ \\
\hline$C_{\max }(\mathrm{pg} / \mathrm{mL})$ & $89.7(15.9)$ & $167(61.5)$ & $666(275)$ \\
\hline$C_{\mathrm{av}}(\mathrm{pg} / \mathrm{mL})$ & $42.7(11.1)$ & $99.3(36.0)$ & $410(168)$ \\
\hline$C_{\min , \mathrm{ss}}(\mathrm{pg} / \mathrm{mL})$ & - & $57.1(22.0)$ & $252(117)$ \\
\hline $\mathrm{AUC}_{\tau}(\mathrm{pg} \cdot \mathrm{h} / \mathrm{mL})$ & 1025 (267) & 2384 (864) & 9847 (4041) \\
\hline$t_{\max }(\mathrm{h})^{\mathrm{a}}$ & $5.91(1.22)$ & $4.91(1.14)$ & $5.37(0.93)$ \\
\hline & $6.00(4.00-8.02)$ & $5.00(2.00-6.00)$ & $5.00(4.00-7.00)$ \\
\hline
\end{tabular}

Data are expressed as mean (standard deviation) unless otherwise specified

${ }^{\text {a }}$ Median (minimum-maximum) also listed

$A U C_{\tau}$ area under the plasma concentration-time curve for one $24 \mathrm{~h}$ dosing interval, $C_{a v}$ average steady-state plasma drug concentration within a dosing interval, $C_{\max }$ maximum plasma concentration, $C_{\text {min,ss }}$ minimum plasma concentration during a dosing interval at steady state, $n$ number of subjects, $S D$ single dose, $S S$ steady state, $t_{\max }$ time to $C_{\max }$

Table 7 Descriptive statistics of pharmacokinetic parameters for cebranopadol (cohorts 2 and 3) following single or multiple doses of cebranopadol (trial 4)

\begin{tabular}{|c|c|c|c|c|}
\hline \multirow[t]{2}{*}{ Parameter (units) } & \multicolumn{4}{|l|}{ Treatment } \\
\hline & $\begin{array}{l}\text { Cohort } 2 \\
400 \mu \mathrm{g} \text { SD (day } 1) \\
(n=12)\end{array}$ & $\begin{array}{l}\text { Cohort } 2 \\
400 \mu \mathrm{g} \text { SS (day } 14) \\
(n=12)\end{array}$ & $\begin{array}{l}\text { Cohort } 2 \\
1200 \mu \mathrm{g} \text { SS (day } 40) \\
(n=7)\end{array}$ & $\begin{array}{l}\text { Cohort } 3 \\
1600 \mu \mathrm{g} \text { SS (day 29) } \\
(n=8)\end{array}$ \\
\hline$C_{\max }(\mathrm{pg} / \mathrm{mL})$ & $145(43.4)$ & $255(130)$ & 891 (397) & 1119 (477) \\
\hline$C_{\mathrm{av}}(\mathrm{pg} / \mathrm{mL})$ & $81.4(25.7)$ & 178 (88.7) & 603 (315) & $783(342)$ \\
\hline$C_{\min , \mathrm{ss}}(\mathrm{pg} / \mathrm{mL})$ & - & $115(56.9)$ & 358 (219) & $524(258)$ \\
\hline $\mathrm{AUC}_{\tau}(\mathrm{pg} \mathrm{h} / \mathrm{mL})$ & 1953 (618) & $4260(2129)$ & $14,474(7564)$ & 18,785 (8197) \\
\hline$t_{\max }(\mathrm{h})^{\mathrm{a}}$ & $6.34(2.15)$ & $6.45(1.44)$ & $6.01(1.16)$ & $8.38(6.42)$ \\
\hline & $6.50(2.00-9.98)$ & $6.04(4.03-10.00)$ & $6.00(4.93-8.00)$ & $6.49(5.00-4.02)$ \\
\hline
\end{tabular}

Data are expressed as mean (standard deviation) unless otherwise specified

${ }^{\text {a }}$ Median (minimum-maximum) also listed

$A U C_{\tau}$ area under the plasma concentration-time curve for one $24 \mathrm{~h}$ dosing interval, $C_{a v}$ average steady-state plasma drug concentration, $C_{m a x}$ maximum plasma concentration, $C_{\text {min,ss }}$ minimum plasma concentration during a dosing interval at steady state, $n$ number of subjects, $S D$ single dose, $S S$ steady state, $t_{\max }$ time to $C_{\max }$ 
Table 8 Descriptive statistics for the derived PK parameters of cebranopadol (trial 5)

\begin{tabular}{lll}
\hline Parameter (units) & Treatment group & \\
\cline { 2 - 3 } & Cebranopadol $600 \mu \mathrm{g}(N=47)$ & Cebranopadol $1600 \mu \mathrm{g}(N=55)$ \\
\hline$C_{\text {max,ss }}(\mathrm{pg} / \mathrm{mL})$ & $361 \pm 161$ & $796 \pm 371$ \\
$\mathrm{AUC}_{\tau, \mathrm{ss}}(\mathrm{pg} \mathrm{h} / \mathrm{mL})$ & $6022 \pm 2655$ & $13,221 \pm 6098$ \\
$t_{\max }(\mathrm{h})$ & $6.00(1.00-14.0)$ & $6.00(3.00-23.9)$ \\
\hline
\end{tabular}

Data are expressed as arithmetic mean \pm standard deviation, except for $t_{\max }$, which is expressed as median (range)

$A U C_{\tau, s s}$ area under the plasma concentration-time curve for one $24 \mathrm{~h}$ dosing interval at steady state, $C_{\max , s s}$ maximum plasma concentration at steady state, $N$ total number of subjects, $P K$ pharmacokinetic, $t_{\max }$ time to $C_{\max }$

Table 9 Concentration profile characteristics of cebranopadol in male and female subjects following a single oral dose of $400 \mu \mathrm{g}$ (trial 6)

\begin{tabular}{llll}
\hline PK parameter & Male subjects (fasted) $(n=5)$ & Female subjects (fasted) $(n=6)$ & Female subjects $($ fed $)(n=6)$ \\
\hline $\mathrm{AUC}_{\mathrm{t}}(\mathrm{ng} \mathrm{h} / \mathrm{mL})$ & $2.31 \pm 1.35$ & $1.48 \pm 0.679$ & $2.03 \pm 0.927$ \\
$C_{\max }(\mathrm{ng} / \mathrm{mL})$ & $0.138 \pm 0.0685$ & $0.112 \pm 0.0464$ & $0.144 \pm 0.0634$ \\
$t_{\max }(\mathrm{h})$ & $6.00(4.00-10.00)$ & $6.00(4.00-6.00)$ & $6.00(4.00-8.00)$
\end{tabular}

Data are expressed as arithmetic mean \pm standard deviation or median (range)

$A U C_{t}$ area under the plasma concentration-time curve from time zero to the last time with a quantifiable concentration, $C_{\max }$ maximum plasma concentration, $n$ number of subjects, $P K$ pharmacokinetic, $t_{\max }$ time to $C_{\max }$

Table 10 ANOVA of PK parameters of cebranopadol following a single oral dose of $400 \mu \mathrm{g}$ in fed and fasted female subjects [ $n=6]$ (trial 6)

\begin{tabular}{|c|c|c|c|c|c|}
\hline Parameter & Food status & ANOVA estimate & $95 \% \mathrm{CI}$ of estimate & ANOVA estimated ratio fed/fasted & $90 \% \mathrm{CI}$ of estimated ratio \\
\hline \multirow[t]{2}{*}{$\mathrm{AUC}_{\mathrm{t}}(\mathrm{ng} \mathrm{h} / \mathrm{mL})$} & Fasted & 1.34 & $0.722-2.50$ & 1.308 & $1.024-1.670$ \\
\hline & Fed & 1.76 & $0.945-3.26$ & & \\
\hline \multirow[t]{2}{*}{$C_{\max }(\mathrm{ng} / \mathrm{mL})$} & Fasted & 0.104 & $0.0635-0.169$ & 1.281 & $1.184-1.386$ \\
\hline & Fed & 0.133 & $0.0814-0.216$ & & \\
\hline
\end{tabular}

ANOVA analysis of variance, $A U C_{t}$ area under the plasma concentration-time curve from time zero to the last time with a quantifiable concentration, $C_{\max }$ maximum plasma concentration, $C I$ confidence interval, $n$ number of subjects, $P K$ pharmacokinetic

At steady state (day 14), mean PTF of cebranopadol concentrations was $110 \%$ and $86.1 \%$ for cebranopadol 200 and $400 \mu \mathrm{g}$, respectively. On days 36,40 and 29 , the mean fluctuation of cebranopadol concentrations was $101 \%$ for cebranopadol $800 \mu \mathrm{g}, 94.3 \%$ for cebranopadol $1200 \mu \mathrm{g}$ and $73.7 \%$ for cebranopadol $1600 \mu \mathrm{g}$, respectively (data on file).

Furthermore, in this patient trial, dose proportionality of $C_{\max }, C_{\min }$ and $\mathrm{AUC}_{\tau}$ at steady state was demonstrated for the entire dose range (200-1600 $\mu \mathrm{g} / \mathrm{day})$ by linear regression analysis (data on file).

\subsubsection{PKs of Cebranopadol After Multiple-Dose Administration in Healthy Subjects (Trial 5)}

The PK properties of cebranopadol after multiple oral dosing were determined in healthy subjects as part of the multiple-dose escalation trial. In healthy subjects, plasma concentrations after multiple oral dosing of cebranopadol peaked at $6 \mathrm{~h}$ postdose (median $t_{\max }$ ) for both dose groups (Table 8). The PTF of cebranopadol concentration was approximately $77 \%$ for both dose groups (data on file).

\subsubsection{Exploration of Food and Sex Effect on the PKs of Cebranopadol in Healthy Subjects (Trial 6)}

As part of the first-in-man trial (Table 1), an exploration into the effect of food on the PKs of cebranopadol in six evaluable female subjects showed that mean $t_{\max }$ was not influenced by food intake, whereas mean $C_{\max }$ and mean $\mathrm{AUC}_{\mathrm{t}}$ were approximately $30 \%$ higher following food intake compared with the fasted state (Table 9). The ANOVA estimates are shown in Table 10.

After cebranopadol doses of $100-800 \mu \mathrm{g}$ in male subjects, plasma concentrations of cebranopadol peaked between 4 and $6 \mathrm{~h}$ postdose (median $t_{\max }$ ) in the doseescalation part [9]. Mean $C_{\max }$ was reached at $6 \mathrm{~h}$ after dosing in both sexes (Table 9). Female subjects showed 
Table 11 ANOVA of sex effects on PK parameters of cebranopadol following a single oral dose of $400 \mu \mathrm{g}$ in male $(n=5)$ and female $(n=6)$ subjects (trial 6)

\begin{tabular}{lllccc}
\hline PK parameter & Sex & ANOVA estimate & 95\% CI of estimate & ANOVA estimated ratio male/female & 90\% CI of estimated ratio \\
\hline AUC $_{\mathrm{t}}(\mathrm{ng} \mathrm{h} / \mathrm{mL})$ & Female & 1.34 & $0.605-2.98$ & 1.227 & $0.471-3.196$ \\
& Male & 1.65 & $0.688-3.94$ & & $0.611-2.174$ \\
$C_{\max }(\mathrm{ng} / \mathrm{mL})$ & Female & 0.104 & $0.0610-0.175$ & 1.153 & \\
& Male & 0.119 & $0.0669-0.213$ & & \\
\hline
\end{tabular}

ANOVA analysis of variance, $A U C_{t}$ area under the plasma concentration-time curve from time zero to the last time with a quantifiable concentration, $C I$ confidence interval, $C_{\max }$ maximum plasma concentration, $n$ number of subjects, $P K$ pharmacokinetic

Table 12 Demographic characteristics of the subject and patient populations included in the population pharmacokinetic analysis ${ }^{\mathrm{a}}$

\begin{tabular}{|c|c|c|c|c|c|c|c|c|}
\hline Trial & $\begin{array}{l}\text { No. of } \\
\text { subjects }\end{array}$ & $\begin{array}{l}\text { Males/ } \\
\text { females }\end{array}$ & $\begin{array}{l}\text { Median age } \\
\text { (years) }\end{array}$ & $\begin{array}{l}\text { Minimum age } \\
\text { (years) }\end{array}$ & $\begin{array}{l}\text { Maximum age } \\
\text { (years) }\end{array}$ & $\begin{array}{l}\text { Median } \\
\text { weight }(\mathrm{kg})\end{array}$ & $\begin{array}{l}\text { Minimum } \\
\text { weight }(\mathrm{kg})\end{array}$ & $\begin{array}{l}\text { Maximum } \\
\text { weight }(\mathrm{kg})\end{array}$ \\
\hline \multicolumn{9}{|l|}{ Phase I } \\
\hline Trial 1 & 24 & $24 / 0$ & 39 & 24 & 49 & 80 & 61 & 96 \\
\hline Trial 2 & 12 & $12 / 0$ & 23.5 & 20 & 43 & 80.9 & 67.2 & 90.8 \\
\hline Trial 3 & 24 & $24 / 0$ & 42 & 21 & 53 & 81 & 68 & 94 \\
\hline Trial 4 & 31 & $17 / 14$ & 39 & 18 & 64 & 78.6 & 52.6 & 120.2 \\
\hline Trial 5 & 111 & $61 / 50$ & 34 & 20 & 45 & 74.4 & 50.6 & 101.2 \\
\hline Trial 6 & 26 & $20 / 6$ & 22.5 & 18 & 40 & 74 & 56 & 92 \\
\hline Trial 7 & 12 & $12 / 0$ & 21.5 & 19 & 26 & 77.2 & 64 & 111 \\
\hline Trial 8 & 47 & $35 / 12$ & 38 & 18 & 52 & 76.2 & 53.6 & 108.3 \\
\hline \multicolumn{9}{|l|}{ Phase IIa } \\
\hline Trial 9 & 161 & $19 / 142$ & 37 & 18 & 61 & 73.9 & 45.4 & 135.2 \\
\hline Trial 10 & 86 & $54 / 32$ & 61 & 32 & 76 & 99 & 61 & 171 \\
\hline Trial 11 & 95 & $29 / 66$ & 62 & 40 & 75 & 86.5 & 56 & 180 \\
\hline Trial 12 & 92 & $62 / 30$ & 60 & 33 & 75 & 92 & 51 & 197 \\
\hline \multicolumn{9}{|l|}{ Phase II } \\
\hline Trial 13 & 385 & $126 / 259$ & 58 & 25 & 79 & 79 & 47 & 136 \\
\hline Trial 14 & 187 & $122 / 65$ & 62.5 & 29 & 79 & 95.9 & 60 & 147.5 \\
\hline
\end{tabular}

${ }^{a}$ Only subjects who received at least one dose of cebranopadol were included in the population pharmacokinetic analysis

lower $C_{\max }$, AUC and $\mathrm{AUC}_{\mathrm{t}}$ than male subjects after administration of cebranopadol $400 \mu \mathrm{g}$. An exploration into the influence of sex on the main PK parameters, conducted using ANOVA, did not indicate a relevant influence of sex on $C_{\max }$ and $\mathrm{AUC}_{\mathrm{t}}$. The ANOVA estimates for sex effects (with 95\% CI) and the ANOVA estimate for the male/female ratios (with $90 \%$ CIs) are summarized in Table 11.

\subsubsection{Population PK Analysis}

Table 12 provides information on the number of subjects used in this population PK analysis, along with their demographics. Subjects who received at least one dose of cebranopadol were included in the analysis. A total of 287 subjects were available from phase I trials, with an age range of 18-64 years (median age 33 years), while a total of 1006 subjects were available from phase II trials, with an age range of 18-79 years (median age 58 years).

Data exploration showing dose-normalized cebranopadol concentrations following administration of escalating doses in healthy subjects did not indicate the presence of dose nonlinearity in cebranopadol PKs (Fig. 2).

A two-compartment disposition model with two lagged transition compartments and first-order elimination process was found to best describe the data and was selected as the base model. The following covariates were tested during model building:

- Cytochrome P450 (CYP) 2D6 phenotype, CYP2C9 phenotype, $\mathrm{CrCl}$, alanine aminotransferase concentration, age, sex and disease status on CL;

- Formulation and food intake on the absorption rate constant; 
Fig. 2 Dose-normalized cebranopadol concentrations versus time after the last dose, stratified by dose in healthy subjects. The smooth fitted line, produced using the locally weighted scatter plot smoothing method, is displayed in red, the blue circles display observed concentrations, and the numbers on the top of the panels indicate the cebranopadol doses (in $\mu \mathrm{g}$ )

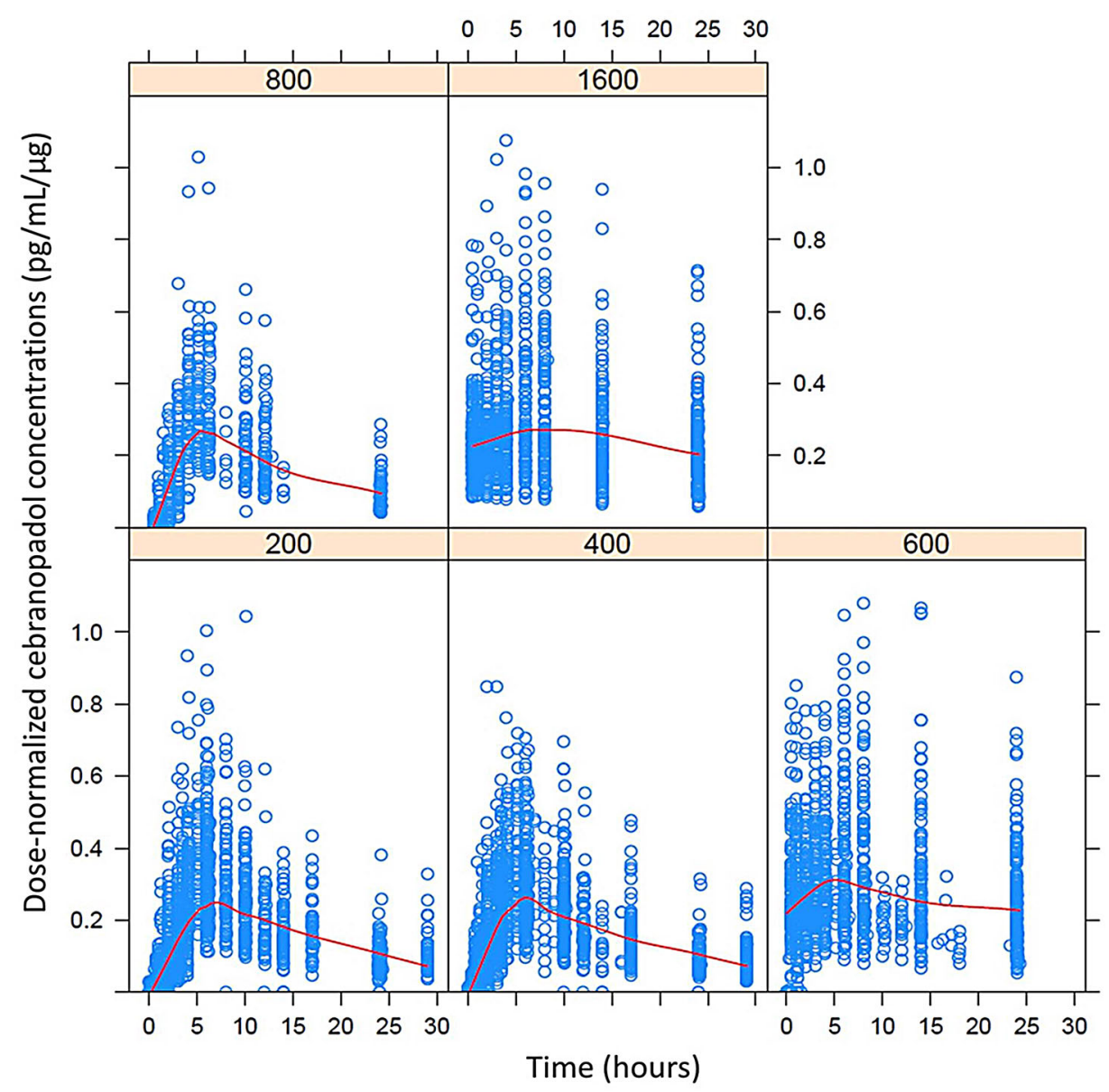

- Formulation on the absorption rate constant of the transition compartment $\left(\mathrm{k}_{\mathrm{lag}}\right)$;

- Disease status and formulation on bioavailability;

- Age on the volume of distribution of the central compartment;

- Weight on the volume of distribution of the peripheral compartment.

The following covariates were found to be significantly correlated with cebranopadol PK parameters:

- $\mathrm{CrCl}$, alanine aminotransferase concentration, sex, and CYP2C9 phenotype (based on $38.3 \%$ of the subjects with known CYP2C9 phenotype) were correlated with apparent CL;

- age was correlated with the volume of distribution of the central compartment;

- body weight was correlated with the volume of distribution of the peripheral compartment;

- formulation and disease status were correlated with bioavailability;

- formulation was correlated with the absorption rate constant and $k_{\text {lag. }}$.
Food intake was not found to be statistically correlated with the absorption rate constant.

Parameter estimates for the final model are shown in Table 13.

Visual predictive check, which was created for the final model after the first cebranopadol dose in healthy subjects, bunionectomy patients, osteoarthritis patients, low back pain patients and diabetic polyneuropathy patients (Fig. 3), indicated an adequate predictive power of the model.

As shown in Table 14, the impact of age and body weight on $C_{\text {max,ss }}$ and $\mathrm{AUC}_{\mathrm{ss}}$ was lower than $3 \%$ with respect to the values of the typical patient considered as reference, whereas the impact of lower $\mathrm{CrCl}$ values accounted for increases in $C_{\text {max,ss }}$ and $\mathrm{AUC}_{\mathrm{ss}}$ up to 30 and $34 \%$ in the investigated range, respectively. Females had $13 \%$ higher $C_{\text {max,ss }}$ and $17 \%$ higher $\mathrm{AUC}_{\mathrm{ss}}$ than males due to the fact that sex significantly correlated with clearance (Table 14). As the histogram in Fig. 4 shows, a considerable overlap exists between the distributions of male and female clearances.

The simulations also indicated that low back pain/osteoarthritis and diabetic polyneuropathy patient 
Table 13 Parameter estimates for the final PK model

\begin{tabular}{|c|c|c|}
\hline Parameter & Estimate (95\% CI) & Interindividual variability (RSE\%) \\
\hline \multicolumn{3}{|l|}{ Clearance } \\
\hline Reference value & 74.3 L/h (67.71-80.88) & $0.412(10.1)$ \\
\hline Males & 87.4 L/h (79.27-95.62) & \\
\hline CYP2C9 extensive metabolizers & $82.4 \mathrm{~L} / \mathrm{h}(75.41-89.53)$ & \\
\hline CYP2C9 poor and intermediate metabolizers & $58.7 \mathrm{~L} / \mathrm{h}(49.48-68.05)$ & \\
\hline Effect of ALT (exponential) & $-0.156(-0.237$ to -0.075$)$ & \\
\hline Effect of $\mathrm{CrCl}$ (exponential) & $0.349(0.202-0.496)$ & \\
\hline \multicolumn{3}{|l|}{ Volume central compartment } \\
\hline Reference value & 225 L (188.152-261.84) & $0.559(20.6)$ \\
\hline Effect of age (exponential) & $-0.446(-0.664$ to -0.228$)$ & \\
\hline \multicolumn{3}{|l|}{ Volume peripheral compartment } \\
\hline Reference value & 6750 L (6150.24-7349.76) & \\
\hline Effect of body weight (exponential) & $0.604(0.247-0.961)$ & \\
\hline Intercompartmental clearance & 84.2 L/h (75.635-92.765) & \\
\hline \multicolumn{3}{|l|}{ Absorption rate constant } \\
\hline Reference value & $0.864 \mathrm{~h}^{-1}(0.755-0.973)$ & $0.519(11.2)$ \\
\hline Oral solution & $2.43 \mathrm{~h}^{-1}(2.07-2.93)$ & \\
\hline Capsules & $2.09 \mathrm{~h}^{-1}(1.58-2.61)$ & \\
\hline \multicolumn{3}{|l|}{$k_{\text {lag }}$} \\
\hline Reference value & $0.087 \mathrm{~h}^{-1}(0.079-0.095)$ & $0.0626(18.8)$ \\
\hline Oral solution & $0.077 \mathrm{~h}^{-1}(0.071-0.99)$ & \\
\hline Capsules & $0.077 \mathrm{~h}^{-1}(0.068-0.99)$ & \\
\hline \multicolumn{3}{|l|}{ Bioavailability } \\
\hline Oral solution & $1.045(0.98-1.11)$ & \\
\hline Capsules & $1.174(1.07-1.278)$ & \\
\hline Healthy volunteers & $0.837(0.759-0.915)$ & \\
\hline Bunionectomy patients & $1.132(1.036-1.228)$ & \\
\hline DPN patients & $1.801(1.605-1.997)$ & \\
\hline
\end{tabular}

For categorical covariates, the most common category is displayed in the table as the reference value

The most common categories were female sex, tablet formulation, disease status of nociceptive pain (osteoarthritis and low back pain), and unknown CYP2C9 phenotype metabolizer status

For bioavailability the reference value was set to 1

$A L T$ alanine transferase, $C I$ confidence interval, $C r C l$ creatinine clearance, $C Y P$ cytochrome $\mathrm{P} 450, D P N$ diabetic polyneuropathy, $k_{\text {lag }}$ absorption rate constant of the transition compartment, $P K$ pharmacokinetic, $R S E$ relative standard error

populations can have up to $29.5 \%$ higher $C_{\mathrm{max}, \mathrm{ss}}$ and $\mathrm{AUC}_{\mathrm{ss}}$ values compared with healthy subjects (Table 14).

\section{Discussion}

The concentration profile of cebranopadol after single oral dosing is characterized by a rather late $t_{\max }(4-6 \mathrm{~h})$, with a resultant gradual increase in concentration, and a long HVD (approximately $15 \mathrm{~h}$ ). Furthermore, the PTF of cebranopadol concentrations was quite low and similar in both healthy subjects and patients with cLBP (77 and 74\%, respectively). Late $t_{\max }$ and long HVD of cebranopadol were confirmed in the population PK analysis by using two transition compartments to model cebranopadol absorption.

The PK characteristics of $t_{\max }$, HVD and PTF observed for cebranopadol administered once daily fit quite well into the generally observed range of values for marketed ER once-daily formulations of opioid analgesics and would support the suitability of cebranopadol for once-daily dosing in the treatment of chronic pain.

Compared with IR opioid formulations, ER opioid formulations are more appropriate to achieve optimal pain control for patients with chronic persistent pain requiring around-the-clock analgesia [2]. The quality of ER formulations can be partially evaluated by assessing the three 

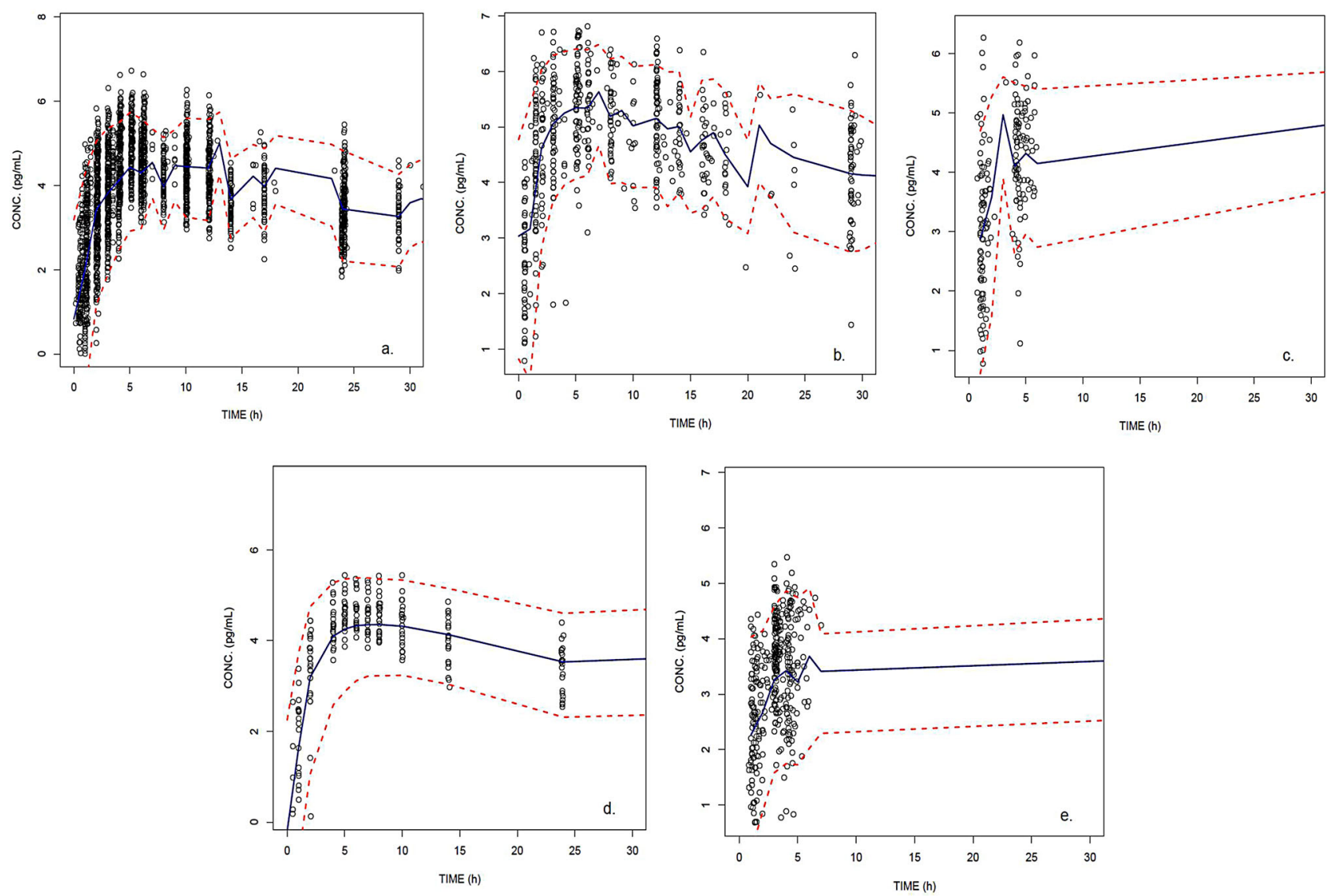

Fig. 3 Visual predictive checks for the final model after the first cebranopadol dose in a healthy subjects, b bunionectomy patients, c osteoarthritis patients, $\mathbf{d}$ low back pain patients, and e diabetic polyneuropathy patients. The circles represent observed concentrations, the dotted red lines represent the 5th and 95th percentiles of the

simulated data, and the solid blue line represents the median of the simulated data. The individual impact of a selected number of significant covariates on cebranopadol exposure was investigated by simulations. CONC. concentration

cebranopadol PK parameters, $t_{\max }$, HVD and PTF, highlighted above. A maximized $t_{\max }$ value induces a more gradual onset of effects and the HVD is a parameter describing the extent of controlled release. If the HVD is too short, this can induce end-of-dose failure. Fluctuation should be as low as possible in order to provide as stable plasma concentrations as possible over a dosing interval [10].

Several oral analgesics are commercially available as ER formulations with a recommended dosing interval of 24 h, e.g. hydromorphone, hydrocodone and morphine.

After administration of single doses of 8,16 or $32 \mathrm{mg}$ of a long-acting osmotic-release oral system (OROS) hydromorphone formulation, the $C_{\max }$ of hydromorphone was achieved after a median of 12.0-16.5 h. Repeated administration of once-daily OROS hydromorphone in healthy subjects was associated with a low fluctuation of approximately $83 \%( \pm 30)$. In patients with chronic pain conditions, the result for the fluctuation obtained in the $16 \mathrm{mg}$

dose group was comparable with that observed for the $16 \mathrm{mg}$ dose group in a multiple-dose trial in healthy subjects [11].

Once-daily dosing of an ER hydrocodone formulation resulted in a mean fluctuation of hydrocodone of $61 \%$ at steady state, with a median $t_{\max }$ in the range of $14-16 \mathrm{~h}$ [12]. In another published trial with hydrocodone ER tablets formulated with different levels of coating, median $t_{\max }$ was reported in the range of 5.9-8.0 $\mathrm{h}$ [13].

A mean fluctuation of $93.4 \%$ and a mean HVD of $18.8 \mathrm{~h}$ was reported for a once-daily morphine sulfate ER formulation $\left(\right.$ Avinza $^{\circledR}$ ) in a multiple-dose PK trial in patients with chronic to moderate/severe pain [14]. In a single-dose PK trial in healthy subjects, Avinza ${ }^{\circledR}$ had a $t_{\max }$ of $6.7 \mathrm{~h}$ [15].

The above mentioned PK characteristics of cebranopadol were observed for a variety of different formulations (tablet, liquid-filled capsule and oral solution). This would also suggest that the potential for tampering of the 
Table 14 Impact of covariates on cebranopadol $600 \mu \mathrm{g}$ exposures for subjects with nociceptive pain (OA and LBP)

\begin{tabular}{|c|c|c|c|c|}
\hline Covariate & $C_{\max , \mathrm{ss}}$ & $\%$ Change in $C_{\mathrm{max}, \mathrm{ss}}$ & $\mathrm{AUC}_{\tau, \mathrm{ss}}(\mathrm{pg} \mathrm{h} / \mathrm{mL})$ & $\%$ Change in $\mathrm{AUC}_{\tau, \mathrm{ss}}$ \\
\hline Reference values & 360.3 & 0 & 6790.1 & 0 \\
\hline Female sex & 408.0 & 13.0 & 7925.5 & 16.7 \\
\hline \multicolumn{5}{|l|}{ Age, years } \\
\hline 40 & 359.1 & -0.3 & 6776.0 & -0.2 \\
\hline 60 & 352.1 & -2.3 & 6751.5 & -0.6 \\
\hline 75 & 353.9 & -1.8 & 6723.1 & -1.0 \\
\hline \multicolumn{5}{|l|}{$\mathrm{CrCl}, \mathrm{mL} / \mathrm{min}$} \\
\hline 45 & 468.8 & 30.1 & 9070.2 & 33.6 \\
\hline 60 & 423.0 & 17.4 & 8231.3 & 21.2 \\
\hline 80 & 391.5 & 8.6 & 7487.1 & 10.3 \\
\hline \multicolumn{5}{|l|}{ Body weight, $\mathrm{kg}$} \\
\hline 70 & 351.7 & -2.4 & 6756.3 & -0.5 \\
\hline 100 & 356.4 & -1.1 & 6764.2 & -0.4 \\
\hline 120 & 354.8 & -1.5 & 6717.3 & -1.1 \\
\hline \multicolumn{5}{|l|}{ Disease status } \\
\hline Healthy & 301.6 & -16.3 & 5683.3 & -16.3 \\
\hline DPN & 407.9 & 13.2 & 7686.4 & 13.2 \\
\hline
\end{tabular}

The titration scheme to reach cebranopadol $600 \mu \mathrm{g}$ is defined as cebranopadol $100 \mu \mathrm{g}$ for 6 days, cebranopadol $200 \mu \mathrm{g}$ for 6 days, cebranopadol $400 \mu \mathrm{g}$ for 6 days and cebranopadol $600 \mu \mathrm{g}$

The reference values for the covariates, defined as the median values for continuous covariates and the most frequent category for categorical covariates, except disease status, were: sex $=$ male, formulation $=$ tablet, CYP2C9 status = unknown, disease status $=\mathrm{LBP}$ and OA patients, age (years) $=55, \mathrm{CrCl}(\mathrm{mL} /$ $\min )=106.4$, body weight $(\mathrm{kg})=82, \mathrm{ALT}$ (units $/ \mathrm{L})=19$

$A L T$ alanine transferase, $A U C_{\tau, s s}$ area under the plasma concentration-time curve for one $24 \mathrm{~h}$ dosing interval at steady state, $C_{\max , s s}$ maximum plasma concentration at steady state, $\mathrm{CrCl}$ creatinine clearance, $C Y P$ cytochrome $\mathrm{P} 450, D P N$ diabetic polyneuropathy, $L B P$ low back pain, $O A$ osteoarthritis

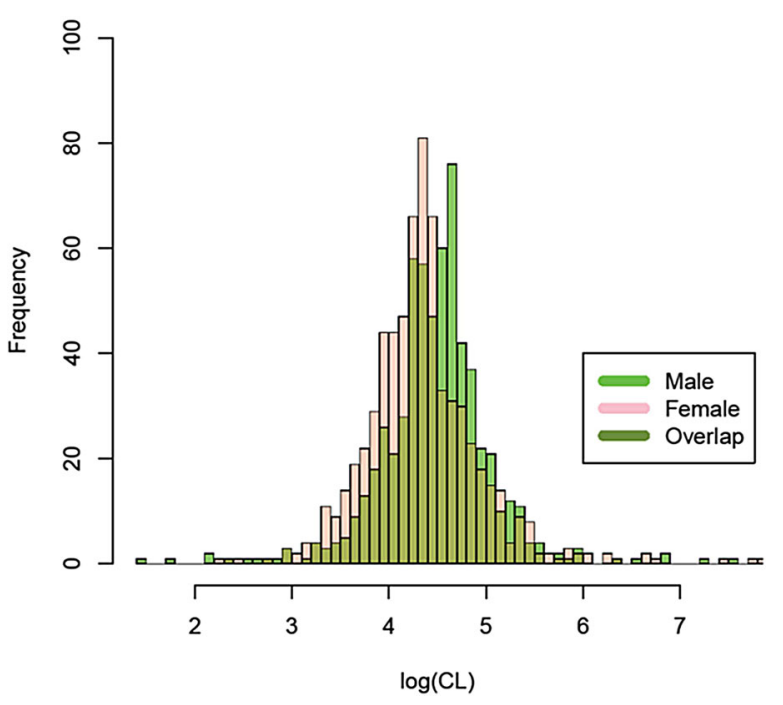

Fig. 4 Histogram of $\log (\ln )$-transformed CL values for males and females. $C L$ clearance

cebranopadol tablet formulation is very limited, which may result in a product with low oral abuse potential.

The apparent ER-like profile observed for cebranopadol from an IR formulation is considered to result from the physicochemical properties of cebranopadol, a Biopharmaceutics Classification System class 2 compound. Cebranopadol is poorly soluble: equilibrium solubility was determined to be $0.14,1.23,0.05$ and $<0.04 \mu \mathrm{g} / \mathrm{mL}$ at $\mathrm{pH}$ values of 1.2, 4.8, 6.8 and 7.4, respectively (data on file). As noted in Sect. 3.2.2 $\left({ }^{14} \mathrm{C}\right.$-radiolabelled trial), the mean dose-normalized AUC for total radioactivity up to $24 \mathrm{~h}$ after both intravenous and oral administration were very similar, suggesting complete absorption and thus high permeability of cebranopadol. The slow absorption rate with a late $t_{\max }$ is thus considered to result from the low solubility of the compound. Therefore, the PK characteristics of cebranopadol are more consistent with an ER profile, which might have the advantage that dose dumping related to failure of the formulation cannot occur. It also has the development advantage that no further efforts in designing a specific ER cebranopadol formulation have been necessary.

The mean terminal phase half-life of cebranopadol was assessed to be in the range of $62-96 \mathrm{~h}$. However, the results of the multiple-dose trial in cLBP patients showed that the half-life relevant to predict exposure to cebranopadol at steady state was approximately $24 \mathrm{~h}$ (operational multiple dosing half-life). The longer terminal phase 
half-life is of relevance to determine the washout period after cessation of dosing. In the same multiple-dose trial in cLBP patients, dose proportionality of exposure to cebranopadol $\left(C_{\max }, C_{\min }\right.$ and $\left.\mathrm{AUC}_{\tau}\right)$ at steady state was also demonstrated over the dosing range of 200-1600 $\mu \mathrm{g}$.

Knowledge of the appropriate half-life of a drug is thus of clinical relevance to reliably predict exposure in a patient after multiple dosing. Using a dosing interval of $24 \mathrm{~h}$, the increased exposure to cebranopadol following multiple dosing for 14 days compared with a single dose AF was approximately twofold. This is in line with the accumulation anticipated and observed for many IR drugs when the dosing interval is matched to the half-life of the drug: an increase in exposure of approximately twofold will be observed at steady state [7]. For cebranopadol, this twofold increase in exposure is covered by its broad therapeutic window; this is supported by a preclinical tolerability profile that is better than that of opioids. This results in a broader therapeutic window for cebranopadol than, for example, morphine [6]. The envisaged therapeutic dose range for cebranopadol is $200-600 \mu \mathrm{g} / \mathrm{day}$, to be reached after an uptitration period.

In the population PK model, absorption and elimination were best described by linear processes confirming the overall linear behaviour of the PKs of cebranopadol across disease indications and healthy populations. Again, this is of relevance to the clinician in practice, enabling prediction of the exposure of cebranopadol in the multiple-dose regimen for the anticipated therapeutic dose range.

The exploration into the effect of food on the PKs of cebranopadol showed that mean $C_{\max }$ and mean $\mathrm{AUC}_{\mathrm{t}}$ were approximately $30 \%$ higher following food intake, which is not considered clinically relevant. These data are supported by the results of the population PK model where food intake was tested as a covariate on the absorption rate constant and was not found to be statistically significant. However, this result should be considered with caution since $77.6 \%$ of subjects in this analysis received unrestricted meals.

A preliminary exploration into the effect of sex did not indicate a relevant influence on the main exposure parameters of cebranopadol. This was supported by the population PK model, which included 617 men and 676 women. Although sex was found to be significantly correlated with the apparent CL of cebranopadol, the modelbased simulations supported the conclusion that the impact of sex on exposure is not clinically relevant.

Preliminary investigations in the first-in-man trial of the effect of food and sex on the PKs of cebranopadol were limited by low subject numbers. Also, in this trial, it was shown that the blood sampling period (up to $72 \mathrm{~h}$ postdose) was insufficient to accurately capture the terminal phase of cebranopadol. As a result, the terminal half-life was initially underestimated. This was subsequently corrected in the relative bioavailability trials with extended sampling up to $336 \mathrm{~h}$ allowing for the terminal half-life to be correctly defined. Nonetheless, the preliminary findings relating to the effects of food and sex were corroborated by the population PK model that was based on much higher subject numbers. Overall, therefore, both clinical PK data and model-based analyses support the recommendation that cebranopadol may be administered to patients without regard to food, and that sex has no relevant impact on exposure to cebranopadol.

Simulations on other potentially relevant covariates indicated that disease status and $\mathrm{CrCl}$ accounted for the largest effects, but that these effects individually would not exceed an overall $35 \%$ change in cebranopadol exposure in the investigated dose range. The impact of these covariates is not considered clinically relevant given the betweensubject variability, and dose adjustment is therefore not deemed necessary.

The clinical PK properties of cebranopadol characterized in this trial are based on six different clinical trials conducted for very specific different reasons, and an overall population PK analysis (including 14 clinical trials). Although, for example, different study populations, different cebranopadol doses and dose regimens, and different PK sampling schemes were used in each trial, this extensive dataset enabled the full characterization of the salient clinical PK properties of cebranopadol.

\section{Conclusion}

Cebranopadol has predictable PKs, and exposure to cebranopadol is comparable in healthy subjects and patients. Although formulated as an IR product, the PK profile of cebranopadol with the late $\mathrm{T}_{\max }$, long HVD, and low fluctuation enables a once-daily administration regimen to be used in clinical practice. Cebranopadol can be administered without regard to food, and the intrinsic factor sex does not have a clinically relevant influence on cebranopadol exposure and derived PK parameters.

Overall, from a PK point of view, cebranopadol seems to offer an attractive treatment option for patients with chronic pain.

Acknowledgements The authors would like to thank M. Brett and K. Göhler, Grünenthal GmbH, Aachen, Germany, for critical review, and D. Ankel-Fuchs, Grünenthal GmbH, Aachen, Germany, for medical writing assistance. The authors would also like to thank all others (too many to name) who were involved in the design or conduct of the trials, or in the collection, analysis or interpretation of the data. 


\section{Compliance with Ethical Standards}

Funding This research was funded by Grünenthal GmbH and Forest Research Institute, Inc. Open access publication of this manuscript was sponsored by Grünenthal GmbH.

Conflicts of interest Elke Kleideiter, Robert Nemeth and Michael Gautrois are employees of Grünenthal GmbH. Chiara Piana was an employee of Grünenthal $\mathrm{GmbH}$ at time of modelling conduct and manuscript writing. Shaonan Wang was an employee of Grünenthal $\mathrm{GmbH}$ at the time of modelling conduct.

Ethical approval All procedures performed in trials involving human participants were in accordance with the ethical standards of the institutional and/or national research committee and with the 1964 Helsinki declaration and its later amendments or comparable ethical standards.

Informed consent Informed consent was obtained from all individual subjects included in the trial.

Open Access This article is distributed under the terms of the Creative Commons Attribution-NonCommercial 4.0 International License (http://creativecommons.org/licenses/by-nc/4.0/), which permits any noncommercial use, distribution, and reproduction in any medium, provided you give appropriate credit to the original author(s) and the source, provide a link to the Creative Commons license, and indicate if changes were made.

\section{References}

1. Zöllner C, Stein C. Opioids. Handbook Exp Pharmacol. 2007;177:31-63.

2. Nicholson B. Primary care considerations of the pharmacokinetics and clinical use of extended-release opioids in treating patients with chronic noncancer pain. Postgrad Med. 2013;125(1):115-27.

3. Kalso E, Edwards JE, Moore RA, McQuay HJ. Opioids in chronic non-cancer pain: systematic review of efficacy and safety. Pain. 2004;112(3):372-80.
4. Cox BM, Christie MJ, Devi L, Toll L, Traynor JR. Challenges for opioid receptor nomenclature. Br J Pharmacol. 2015;172:317-23.

5. Schröder W, Lambert DG, Ko MC, Koch T. Functional plasticity of the N/OFQ-NOP receptor system determines analgesic properties of NOP receptor agonists. $\mathrm{Br} \quad \mathrm{J}$ Pharmacol. 2014;171:3777-800.

6. Linz K, Christoph T, Tzschentke TM, Koch T, Schiene K, Gautrois $\mathrm{M}$, et al. Cebranopadol: a novel potent analgesic Nociceptin/Orphanin FQ peptide and opioid receptor agonist. J Pharmacol Exp Ther. 2014;349:535-48.

7. Sahin S, Benet L. The operational multiple dosing half-life: a key to defining drug accumulation in patients and to designing (extended release dosage forms). Pharm Res. 2008;25(12):2869-77.

8. Cockcroft DW, Gault MH. Prediction of creatinine clearance from serum creatinine. Nephron. 1976;16(1):31-41.

9. Fussen R, Nemeth R, Ossig J, Boinpally R. Single-dose pharmacokinetics and relative bioavailability of the novel strong analgesic cebranopadol [abstract no. WIP-0199]. 7th World Congress, World Institute of Pain; 7-10 May 2014: Maastricht.

10. Güttler K. Opioid effects: galenics make the difference. Anasthesiol Intensivmed Notfallmed Schmerzther. 2012;47(4):224-30.

11. Turgeon J, Gröning R, Sathyan G, Thipphawong J, Richarz U. The pharmacokinetics of a long-acting OROS hydromorphone formulation. Expert Opin Drug Deliv. 2010;7(1):137-44.

12. Kapil RP, Cipriano A, Wen W, Yu Lynch S, He E, Colucci SV, et al. Pharmacokinetic profile and sustained 24-hour analgesia of a once-daily hydrocodone bitartrate extended-release tablet with abuse-deterrent properties. Clin Ther. 2016;38(2):302-14.

13. Darwish M, Bond M, Tracewell W, Robertson P Jr, Yang R. Pharmacokinetics of hydrocodone extended-release tablets formulated with different levels of coating to achieve abuse deterrence compared with a hydrocodone immediate-release/ acetaminophen tablet in healthy subjects. Clin Drug Investig. 2015;35(1):13-22.

14. Caldwell JR. Avinza ${ }^{\circledR}:$ 24-h sustained-release oral morphine therapy. Expert Opin Pharmacother. 2004;5(2):469-72.

15. Royal M. A head-to-head, single-dose trial of KADIAN ${ }^{\circledR}$ vs AVINZA $^{\circledR} 30 \mathrm{mg}$ in healthy, opioid-naïve subjects in the fed state: comparison of pharmacokinetics [abstract no. 732]. J Pain. 2005;6:S41. 